\title{
Impact of Gas Turbine Flexibility Improvements on Combined Cycle Gas Turbine Performance
}

\author{
${ }^{1}$ Kamal Abudu \\ ${ }^{1 *}$ Uyioghosa Igie \\ ${ }^{1}$ Ioannis Roumeliotis \\ ${ }^{2}$ Richard Hamilton \\ ${ }^{1}$ School of Aerospace, Transport and Manufacturing \\ Cranfield University \\ Cranfield, Bedfordshire, MK43 0AL \\ United Kingdom \\ *Email: u.igie@cranfield.ac.uk \\ ${ }^{2}$ Mitsubishi Hitachi Power Systems Europe \\ The Point, 37 North Wharf Road \\ London, W2 $1 \mathrm{AF}$ \\ United Kingdom
}

\begin{abstract}
The improvement of gas turbines flexibility has been driven by more use of renewable sources of power due to environmental concerns. There are different approaches to improving gas turbine flexibility, and they have performance implications for the bottoming cycle in the combined cycle gas turbine (CCGT) operation. The CCGT configuration is favourable in generating more power output, due to the higher thermal efficiency that is key to the economic viability of electric utility companies. However, the flexibility benefits obtained in the gas turbine is often not translated to the overall CCGT operation. In this study, the flexibility improvements are the minimum environmental load (MEL) and ramp-up rates, that are facilitated by gas turbine compressor air extraction and injection, respectively. The bottoming cycle has been modelled in this study, based on the detailed cascade approach, also using the exhaust gas conditions of the topping cycle model from recent studies of gas turbine flexibility by the authors. At the design full load, the CCGT performance is verified and subsequent off-design cases from the gas turbine air extraction and injection simulations are replicated for the bottoming cycle. The MEL extension on the gas turbine that brings about a reduction in the engine power output results in a higher steam turbine power output due to higher exhaust gas temperature of the former. This curtails the extended MEL of the CCGT to 19\% improvement, as opposed to $34 \%$ for the stand-alone gas turbine. For the CCGT ramp-up rate improvement with air injection, a 51\% increase was attained. This is 3\% point lower than the standalone gas turbine, arising from the lower steam turbine ramp-up rate. The study has shown that the flexibility improvements in the topping cycle also apply to the overall CCGT, despite constraints from the bottoming cycle.
\end{abstract}

Keywords: flexibility, gas turbine, MEL, ramp-up rate, power augmentation 


\section{Introduction}

The need for a cleaner environment and sustainable energy has resulted in increased subscription to renewable energy sources. In electricity generation, these sources are expected to contribute almost $50 \%$ of the total power generated by 2050 as shown in Figure 1A. While this aims to address environmental concerns, it is a challenge for conventional fossil-fuelled plants. Of these plants, gaspowered engines are preferred as they offer better emissions footprint and thermal efficiency in combined cycle configuration. The intermittency associated with power generation from renewable sources is common knowledge. With an increased subscription to these sources, conventional plants need to compensate for the intermittence with increased flexibility to stabilize the electricity grid. Figure 1B presents the electricity demand and generation schedule for wind with solar, and gas generated power during a 48 hour period in Great Britain (GB) in 2020. The figure shows the capability of the gas-powered engine to follow the demand profile closely at high and minimum capacity operation. It also shows the decline in renewable capacity which coincides with increased electricity demand that requires a timely response from gas-powered plants. This highlights the importance of increased flexibility for gas generated power that is dominated by combined cycle gas turbines (CCGT).

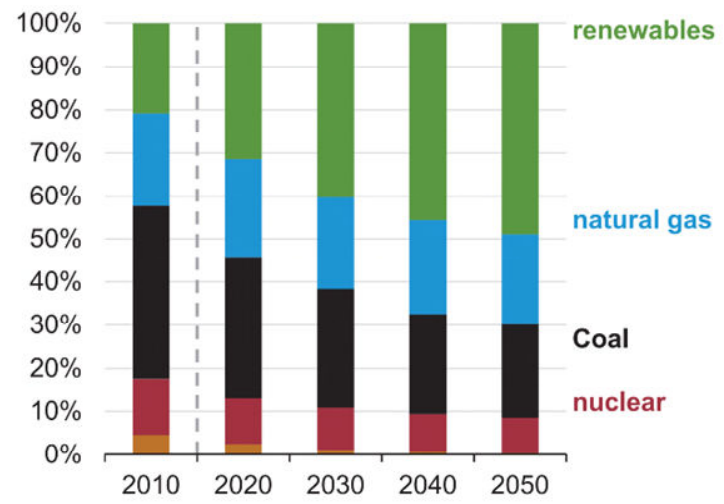

Figure 1A: Projected electric power generation by source [1]

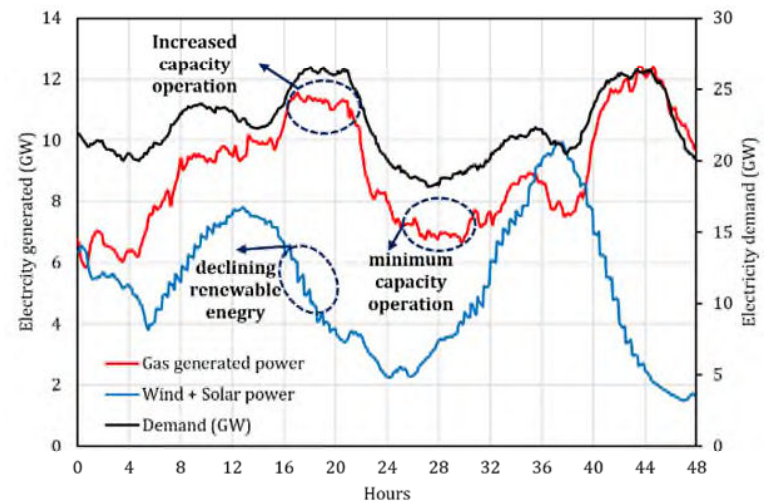

Figure 1B: Demand and power generation schedule for wind, solar and gas plants [2]

Capabilities such as the minimum environmental load (MEL) and ramp rates determine the flexibility of gas turbine (GT)s, as well as CCGT operations. The MEL is defined as the minimum power output of the GT (topping cycle) that complies with emissions requirements, specifically the CO limit. It is desirable to have a low MEL as it enables low load operations that avoid expensive shutdowns during low electricity demand and/or increased renewable capacity. The MEL in the topping cycle subsequently leads to an overall MEL or CCGT MEL when the GT reaches its CO limit. As for the ramp rate, it indicates the responsiveness of the plant to varying power demand, typically concerning an 
increase in load. This is particularly useful when there is a sudden loss in power in the grid due to trips or when there is a shortfall in renewable capacity.

To improve flexibility, original equipment manufacturers (OEMs) and researchers continually explore methods to reduce MEL and increase ramp-up rates. Ruchti et al. [3] explored the extension of engine turndown using a two-staged combustion system. During a low load operation, the engine turns off its sequential "EV" burners to achieve a higher firing temperature that enables acceptable CO emissions. The operation achieved an MEL of $20 \%$ for the engine in CCGT configuration. However, the study does not reflect the impact of the low load operation on the bottoming cycle of a CCGT. For Siemens, Nag et al. [4] investigated the increase in compressor bleed air and combustor bypass to enrich combustion and limit CO production on a G and F class engine. The technology, called "LLCO", maintains a high firing temperature at low load operation by maintaining a high FAR in the combustor and cooling the flue gas before the turbine inlet. The method achieved a reduction of MEL from $70 \%$ to $28 \%$ of power output with CO catalytic reduction, and $40 \%$ without it. The authors indicated an acceptable CCGT operation while speculating better lifing for the HRSG as cycling is avoided. In a similar approach, Ansaldo Energy extended the MEL of an engine using the bleed-off valves (BOV) bleed lines. The operation extracts compressor air from the middle stages and injects it behind the burner to enrich combustion. The study also analyses bleed port behaviour using CFD. An extension of $8 \%$ was obtained for the MEL, which could be further extended using secondary air system variation and anti-icing mechanisms. Although the article did not consider the implication of the extended MEL on a CCGT configuration, it was proposed for further work [5].

A power station operator, Stadtwerke München (SWM) also explored MEL extension for their GE engines in a study by Rouwenhorst et al. [6]. The proposed method involved lowering a controlled temperature to facilitate premixed combustion at low loads. The operators then reduced the load while monitoring CO emissions and combustor dynamics until a new MEL was achieved. The work shows a $20 \%$ extension of MEL to $40 \%$ of GT load, but the effect on a steam cycle was not indicated. Researchers, as well, have sought methods to extend MEL by integrating a storage system with the GT or CCGT. Wojcik and Wang [7] performed a feasibility study on the integration of an adiabatic compressed air energy storage (ACAES) system with a CCGT. The system reduces minimum load by transferring compressor flow and power to the ACAES during low demand. A minimum load of 20\% was achieved although no estimation of emissions was performed. However, the study does not highlight the bottoming cycle performance during the low load extension. Abudu et. al [8] explores the use of compressed air extraction (for storage) to extend stand-alone GT MEL. The method deploys 
airflow extraction behind the compressor section after VIGV closure. This was also achieved maintaining the combustor mean temperature throughout the load reduction. Emissions of pollutants were also evaluated to ascertain environmental compliance. The work shows a MEL extension of $34 \%$ with $24 \%$ of air extraction (with respect to the compressor discharge).

With regards to ramp-up rate improvements, OEMs have mostly considered engine and system redesign, while researchers have explored integrating storage systems with engines. Balling [9] in a study for Siemens energy explains the procedures, testing, and results that enabled a reduction in start-up time and increased allowable start-ups. The study is based on the first and second generation of the FACY (fast cycling) concept that reduced start-up time from 100 minutes to below 40 minutes. The reduction is facilitated by increased automation of the system, optimized control, stack damper installation, once through HRSG and auxiliary steam recirculation. The study also addresses the potential concern for increased thermal transient on thick-walled components specifically the evaporator drum by using a once-through steam generator. Decampli et al. [10] present the improvements achieved by a hybrid GT that consists of a 50MW LM6000 aeroderivative engine and a battery energy storage system (BESS) of 10MW. The study shows that the BESS facilitates the smooth running of the GT by reducing the thermal transient on the turbine blades during ramping. This enables the hybrid system to ramp-up rapidly and certifies it as a non-spinning reserve. The already high GT ramp rate was further improved by the BESS system.

Other works include that of Kim et al. [11] and Abudu et al. [12] that directly address ramp rate improvements. Kim et al. [11] focus on the integration of a GT (in standalone and combined cycle) with a compressed air energy storage (CAES) system to improve the ramp-up. The study concentrates on maintaining the combustion temperature while improving the ramp-up through air injection into the plenum. The injection schedule was also optimized to minimize the deviation of turbine inlet temperature from the design ramp-up. Abudu et al [12] relate the varied amount of air injected with the improvement of the ramp-up rate. The study also considers two ramp-up strategies: one involving the variation of combustion temperature and another that adds VIGV variation. Both methods improved the ramp rate by $10 \%$ for every $2 \%$ air injected. Perri [13] implemented air injection for power augmentation and ramp rate improvements in practice. The study integrates multi-stage intercooled centrifugal compressors with a GT. The compressors feed the GT with compressed air that improves its output and can support ramping. Each compressor module adds 5MW to the engine at ISO conditions; and starts up to full load in a minute that consists of 10 seconds for ramp-up. This provides an additional $30 \mathrm{MW} / \mathrm{min}$ to the ramping capacity of the GT considering 
the contributed power and ramp-up time (of the compressor). The authors further suggest that despite the fast response from the GT, slower responses are expected in combined cycle configuration.

The open literature shows that the much-needed flexibility improvements for the gas engines have mainly focused on the topping cycle, thereby relegating the impact on the bottoming cycle and hence overall CCGT performance. As most gas plants today operate in combined cycle configuration, it becomes crucial to explore the impact of different flexibility improvement strategies on the bottoming cycle to establish if the benefits on the GT amount to an overall CCGT flexibility improvement. This study builds upon the flexibility benefits recorded in Abudu et al [8] and Abudu et al [12] that focus on MEL and ramp-up rate improvements respectively for the stand-alone GT engine. The referred studies present detailed description of how the MEL extension and ramp rate improvement were achieved on the standalone GT using airflow extraction and injection, respectively. The current study explores the implication of these flexibility benefits on a CCGT by matching a bottoming cycle with the previously developed standalone GT (topping cycle). The work presented here, for the first time has shown:

- the implications of GT MEL extension (through air extraction) on CCGT flexibility and performance of the bottoming cycle.

- cost-benefit analysis of extended MEL for CCGT, that is related to spinning reserves in a loadfollowing mode

- the influence of GT ramp-up rate on CCGT flexibility and performance that is relevant to the ancillary market (for frequency response).

\section{Cycle under investigation}

The generic combined cycle plant considered for this study is inspired by the CCGT configuration for a Mitsubishi M501F engine, though only the bottoming cycle is modelled in this study. In practice, the topping cycle engine (M501F) is a 185.4MW single-shaft engine with a thermal efficiency of 37\%. In CCGT mode it is $285.1 \mathrm{MW}$ and $57.1 \%$ respectively. The engine consists of a $16: 1$ pressure ratio compressor, a 16 can combustor and a 4 stage turbine and has been modelled thermodynamically in Abudu et al. [8]. It has been considered that the referred model is the topping cycle for the plant presented here. Hence the bottoming cycle (HRSG and steam turbine) has been developed to match the conditions of the topping cycle engine. The detailed engine model was developed using Turbomatch: a Cranfield university in-house software for simulating different configurations of the GT engine and their performance, in a wide range of operations. 
The HRSG and steam turbine modelled here is based on the detailed approach as shown in Dechamps [14]. The detailed approach in the referred work is centred on the calculation of the thermodynamics and heat transfer in the HRSG and steam turbine in a stepwise method, as shown in the equations presented subsequently. As well, the detailed approach provides insight about the steam conditions across the HRSG and steam turbine. This is contrary to the global approach that is based on high-level system performance, mainly thermal efficiencies of the gas turbine, HRSG and steam turbine. In addition, a cascade configuration is selected for the HRSG to reduce the computational complexity of the model. A triple pressure non-reheat HRSG has been considered for simplification, due to the negligible influence in this type of study. The steam turbine is also of three pressure levels, with high-pressure, intermediate-pressure and low-pressure steam directed into their respective turbines from the HRSG as depicted in Figure 2.

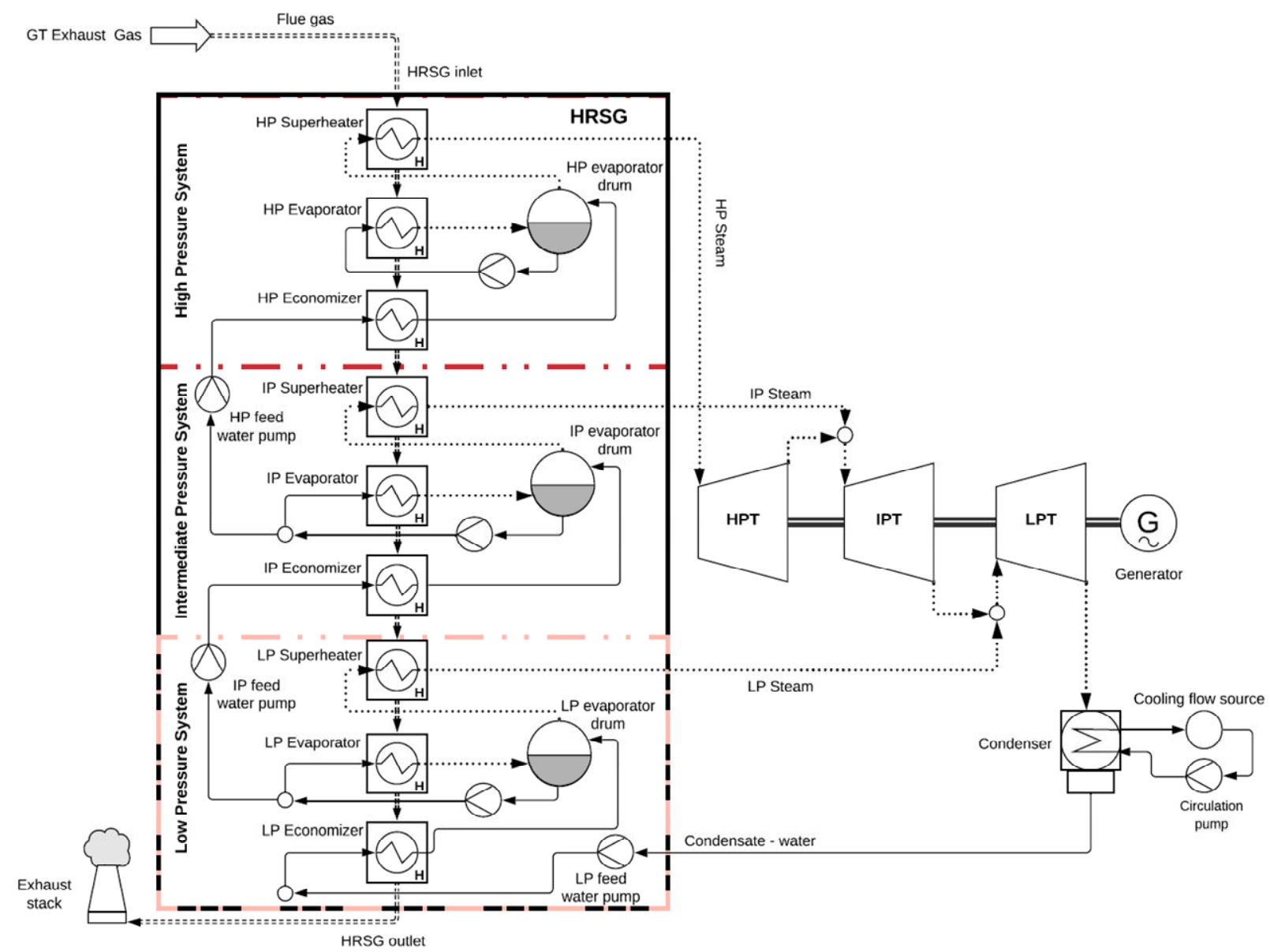

Figure 2: Schematic of the bottoming cycle modelled 
The computational procedure of the bottoming cycle starts with an estimation of the specific heat capacity $\left(c_{p}\right)$ of the GT exhaust gas.

$$
\begin{gathered}
\mathrm{c}_{\mathrm{p}}=\frac{\left(\mathrm{a}+\mathrm{bT}_{g}+\mathrm{cT}_{g}^{2}+\mathrm{dT}_{g}^{3}\right)}{\text { molar mass of gas }} \\
\mathrm{c}_{\mathrm{p}} \text { exhaust gas }=\sum \mathrm{c}_{\mathrm{p}} \cdot \text { volume fraction }
\end{gathered}
$$

Equation 1

Equation 2

Equation 1 presents a correlation that relates the gas temperature $\left(\mathrm{T}_{\mathrm{g}}\right)$ and molar masses of its constituents to their respective specific heat capacities. The expected constituents of flue gas (from complete combustion), their volume fraction, molar masses and constants for the equation are presented in Table 1 (in appendix). The actual specific heat capacity for the exhaust gas is computed using Equation 2 that sums the specific heat capacities of the constituents based on their volume fractions. Accounting for almost complete combustion of natural gas, the resulting specific heat capacity was recalibrated in the model to achieve the required performance.

Table 1: Properties of constituents of flue gas with constants

\begin{tabular}{|c|c|c|c|c|c|c|}
\hline Gas & Molar mass(g) & Volume fraction (\%) & $\mathrm{a}$ & $\mathrm{b}$ & $\mathrm{c}$ & $\mathrm{d}$ \\
\hline Carbon dioxide & 44.01 & $9 \%$ & 22.26 & 0.05981 & $-4 \mathrm{E}-05$ & $7.469 \mathrm{E}-09$ \\
\hline Water & 18.02 & $16 \%$ & 32.24 & 0.001923 & $1.1 \mathrm{E}-05$ & $-3.595 \mathrm{E}-09$ \\
\hline Oxygen & 31.9988 & $3 \%$ & 25.48 & 0.0152 & $-7 \mathrm{E}-06$ & $1.312 \mathrm{E}-09$ \\
\hline Nitrogen & 28.0134 & $72 \%$ & 28.9 & -0.001571 & $8.1 \mathrm{E}-06$ & $-2.873 \mathrm{E}-09$ \\
\hline
\end{tabular}

The HP steam properties, condenser operating pressure, steam turbine isentropic efficiencies, evaporator pinch and approach points temperatures are specified based on best practice [14]. Figure 3 shows the heat transferred between the exhaust gas and generated steam in a HP section; only one section is shown for brevity. It also shows the pinch and approach temperatures with the heat transferred above and below pinch indicated. The temperatures at point's $\mathrm{c}$ and $\mathrm{b}$ are the same (as no temperature change is expected in the evaporator) and are equal to the saturation temperature $\left(\mathrm{T}_{\text {sat }}\right)$ at the selected steam pressure. 


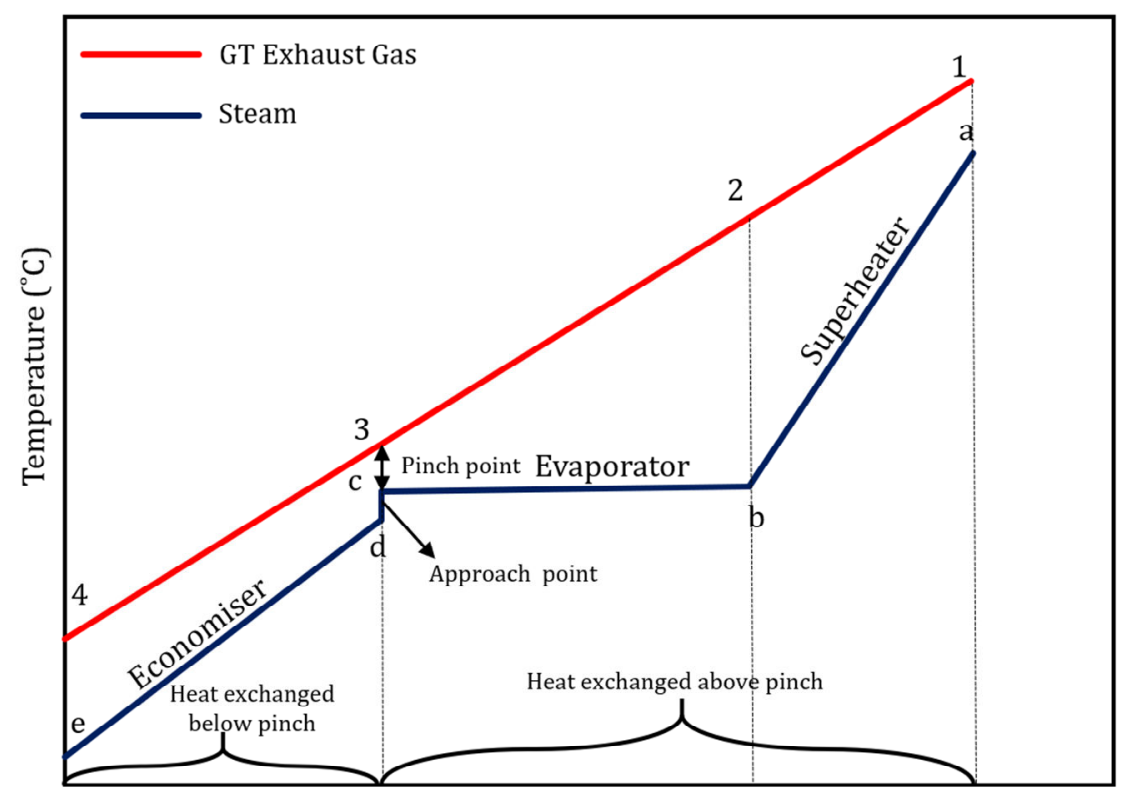

Heat transferred

Figure 3: Single pressure HRSG heat transfer chart

$$
\begin{array}{lr}
\mathrm{T}_{3}=\mathrm{T}_{\mathrm{c}}+\Delta \mathrm{t}_{\mathrm{p}} & \text { Equation 3 } \\
\mathrm{T}_{\mathrm{d}}=\mathrm{T}_{\mathrm{c}}-\Delta \mathrm{t}_{\mathrm{a}} & \text { Equation 4 }
\end{array}
$$

The gas temperature at the evaporator exit $\left(\mathrm{T}_{3}\right)$ is calculated by adding the pinch temperature difference $\left(\Delta \mathrm{t}_{\mathrm{p}}\right)$ to the saturation steam temperature as shown in Equation 3. Similarly, from Equation 4, the steam temperature at the economizer discharge $\left(\mathrm{T}_{\mathrm{d}}\right)$ is found by subtracting the approach point temperature difference $\left(\Delta t_{a}\right)$ from the steam saturation temperature.

$$
\begin{gathered}
\mathrm{Q}_{1-3}=\mathrm{W}_{\mathrm{g}} \cdot \mathrm{c}_{\mathrm{p}} \cdot\left(\mathrm{T}_{1}-\mathrm{T}_{3}\right) \\
\mathrm{W}_{\mathrm{s}}=\frac{\mathrm{Q}_{1-3}}{\left(\mathrm{~h}_{\mathrm{a}}-\mathrm{h}_{\mathrm{d}}\right)}
\end{gathered}
$$

Equation 5

Equation 6

The heat transferred above the pinch point $\left(Q_{1-3}\right)$ is computed by Equation 5 using the exhaust gas flow $\left(\mathrm{W}_{\mathrm{g}}\right)$, specific heat capacity $\left(\mathrm{c}_{\mathrm{p}}\right)$, and the gas temperature difference between the superheater inlet (1) and evaporator exit (3). Assuming all heat transferred is absorbed by the steam, the steam flow $\left(W_{s}\right)$ is then computed as shown in Equation 6, where $h_{a}$ and $h_{d}$ are enthalpies of steam at point a and d respectively (wrt Figure 3).

$$
\mathrm{Q}_{3-4}=\mathrm{Q}_{\mathrm{e}-\mathrm{d}}=\mathrm{W}_{\mathrm{s}} \cdot\left(\mathrm{h}_{\mathrm{d}}-\mathrm{h}_{\mathrm{e}}\right)
$$

\section{Equation 7}




$$
\mathrm{T}_{4}=\mathrm{T}_{3}-\frac{\mathrm{Q}_{3-4}}{\mathrm{C}_{\mathrm{p}} \cdot \mathrm{W}_{\mathrm{g}}}
$$

\section{Equation 8}

The heat below pinch $\left(\mathrm{Q}_{3-4}\right)$ is then computed from Equation 7 using the steam flow and enthalpy difference between points $d$ and e. This facilitates the computation of the gas temperature at the economizer exit $\left(\mathrm{T}_{4}\right)$ that defines the gas temperature into the following HRSG pressure level, using Equation 8.

$$
\begin{gathered}
\Delta \mathrm{h}_{\mathrm{st}} \text { is }=\mathrm{h}_{\mathrm{a}}-\mathrm{h}_{0} \text { (is) } \\
\mathrm{PO}_{\mathrm{ST}}=\Delta \mathrm{h}_{\mathrm{st}}(\text { is }) \cdot \mathrm{W}_{\mathrm{s}} \cdot \eta_{\mathrm{ST}}
\end{gathered}
$$

Equation 9

Equation 10

The isentropic turbine work $\left(\Delta \mathrm{h}_{\mathrm{st}} \mathrm{is}\right)$ is calculated from Equation 9 where $\mathrm{h}_{\mathrm{o}}$ is the isentropic enthalpy at the turbine exit. With the specified steam turbine efficiencies, calculated steam flow and isentropic work, the actual turbine power output $\left(\mathrm{PO}_{\mathrm{ST}}\right)$ is defined by Equation 10. A similar procedure is repeated for the subsequent pressure levels to achieve the total power generated from the steam cycle.

$$
\begin{gathered}
\eta_{\mathrm{CC}}=\eta_{\mathrm{GT}} \cdot \frac{\left(\mathrm{PO}_{\mathrm{GT}}+\mathrm{PO}_{\mathrm{STT}}\right)}{\mathrm{PO}_{\mathrm{GT}}} \\
\eta_{\mathrm{HRSG}}=\frac{\left(\mathrm{T}_{\text {HRSGinlet }}-\mathrm{T}_{\mathrm{HRSGoutlet}}\right)}{\left(\mathrm{T}_{1}-\mathrm{T}_{\mathrm{amb}}\right)} \\
\eta_{\mathrm{R}}=\frac{\mathrm{PO}_{\mathrm{STT}}}{\left(\left(\mathrm{T}_{\text {HRSGinlet }}-\mathrm{T}_{\text {HRSGoutlet }}\right) \cdot \mathrm{C}_{\mathrm{p}} \cdot \mathrm{W}_{\mathrm{g}}\right.}
\end{gathered}
$$

\section{Equation 11}

Equation 12

Equation 13

The efficiencies of the CCGT, HRSG and steam cycle are presented in Equation 11-to Equation 13. Where $\mathrm{PO}_{\text {sтT }}$ is the total power output of the HP, IP and LP steam turbines.

For off design computations, the steam turbines are assumed choked and the Stodola relation shown in Equation 14 holds. This enables the variation of steam pressures and flows during off-design computation. It is important to note that a temperature difference limiter is set for the HP steam temperature that must be at least $20^{\circ} \mathrm{C}$ cooler that the exhaust gas temperature of the GT.

$$
\frac{\mathrm{W}_{\mathrm{s}} \cdot \sqrt{\mathrm{T}_{\mathrm{a}}}}{\mathrm{P}}=\text { constant }
$$

\section{Equation 14}

Table 2 presents the design and performance parameters of the CCGT. Details of the referenced and validated GT model from Abudu et al. [8] at the design point is highlighted. The HRSG and steam cycle performance modelled in this study is also shown, within indication of the specified parameters 
based on OEM specifications and best practice, as well as the outcomes of the calculations. At the bottom of the table is the overall cycle performance that has been compared with the OEM value CCGT plant. The data comparison shows consistency between OEM data and model output that verifies the developed model. It should be noted that the focus of the analysis is the plant performance with regards to changes in power output, efficiency, and steam properties. As a result, peripheral components such as pumps and condensers have been excluded from the analysis.

\begin{tabular}{|c|c|c|c|}
\hline \multirow{2}{*}{$\begin{array}{l}\text { Gas Turbine performance [8] } \\
\text { Inlet mass flow }(\mathrm{kg} / \mathrm{s})\end{array}$} & \multirow{2}{*}{ Values } & \multicolumn{2}{|c|}{ specificationy outcome } \\
\hline & & $\checkmark$ & \\
\hline Pressure ratio & 16 & $\checkmark$ & \\
\hline Combustor mean temperature $(\mathrm{K})$ & 1786 & $\checkmark$ & \\
\hline Compressor efficiencies & $87 \%$ & $\checkmark$ & \\
\hline Turbine efficiency & $89 \%$ & $\checkmark$ & \\
\hline Combustor efficiency & $99 \%$ & $\checkmark$ & \\
\hline Fuel- Natural gas LHV (MJ/kg) & 45.5 & $\checkmark$ & \\
\hline Exhaust gas mass flow (kg/s) & 468 & & $\checkmark$ \\
\hline Exhaust gas temperature (K) & 895 & & $\checkmark$ \\
\hline Exhaust gas pressure (bar) & 1.03 & & $\checkmark$ \\
\hline Power output (MW) & 185.4 & & $\checkmark$ \\
\hline Thermal efficiency & $37 \%$ & & $\checkmark$ \\
\hline \multicolumn{4}{|l|}{ Steam cycle performance } \\
\hline HP steam pressure (bar) & 100 & $\checkmark$ & \\
\hline HP steam temperature $(\mathrm{K})$ & 813 & $\checkmark$ & \\
\hline IP steam pressure (bar) & 10 & $\checkmark$ & \\
\hline IP steam temperature $(\mathrm{K})$ & 477 & & $\checkmark$ \\
\hline LP steam pressure (bar) & 1 & $\checkmark$ & \\
\hline LP steam temperature $(\mathrm{K})$ & 381 & & $\checkmark$ \\
\hline stack temperature $(\mathrm{K})$ & 334 & & $\checkmark$ \\
\hline Pinch point temperature difference $(\mathrm{K})$ & 10 & $\checkmark$ & \\
\hline Approach point temperature difference(K) & 2 & $\checkmark$ & \\
\hline Exit steam quality & $86 \%$ & & $\checkmark$ \\
\hline steam turbine efficiencies & $85 \%$ & $\checkmark$ & \\
\hline CCGT Performance & Model & OEM data [15] & Error $(\%)$ \\
\hline GT Exhaust gas flow (kg/s) & 468 & 468 & $0.0 \%$ \\
\hline GT Exhaust gas temperature $(\mathrm{K})$ & 895.3 & 886 & $-1.0 \%$ \\
\hline GT Power output (MW) & 185.4 & 185.4 & $0.0 \%$ \\
\hline
\end{tabular}




\begin{tabular}{|l|c|c|c|} 
GT Efficiency & 37 & 37 & $0.0 \%$ \\
\hline CCGT Power output (MW) & 285.1 & 285.1 & $0.0 \%$ \\
\hline CCGT Efficiency & 56.9 & 57.1 & $0.4 \%$ \\
\hline Steam cycle efficiency & $35.4 \%$ & - & - \\
\hline HRSG efficiency & $92.5 \%$ & - & - \\
\hline
\end{tabular}

\section{MEL Extension through Extraction on GT}

The extraction of airflow from the GT (as depicted in Figure 4) has an impact on emissions and the potential to extend the MEL as shown in Abudu et al. [8]. The left of Figure 5 shows the strategy deployed for the GT from the referred study. The design MEL of the GT was achieved through VIGV closure (at constant Combustor Mean Temperature - CMT) in phase one. The CMT is the mean temperature rise in the combustor, thereby representing the burner temperature. For phase two, only the CMT is reduced and stopped at the point where the CO limit is reached. The extended MEL (E-MEL) deploys a different approach; the VIGV is closed (phase 1), followed by the air extraction in phase 2 until identical CO limit is reached. For this case, the CMT is fixed throughout the process. Their Exhaust Gas Temperatures (EGT) and Exhaust Gas Flows (EGF) are shown on the right of the figure. This side of the figure shows the percentage change of the parameters for the respective operations. It can be observed that the design MEL has a larger drop in EGT than the E-MEL case. This is a result of the drop in the CMT for MEL case; nevertheless, the E-MEL has a fixed CMT and the EGT reduces slightly. Air extractions reduce the expansion in the turbine due to high CMT and low turbine flow associated with reduced pressure ratio. Larger drops in the EGF are seen for the E-MEL case, resulting from airflow extractions in the engine. These variations alter the steam conditions in the bottoming cycle that impacts the CCGT performance.

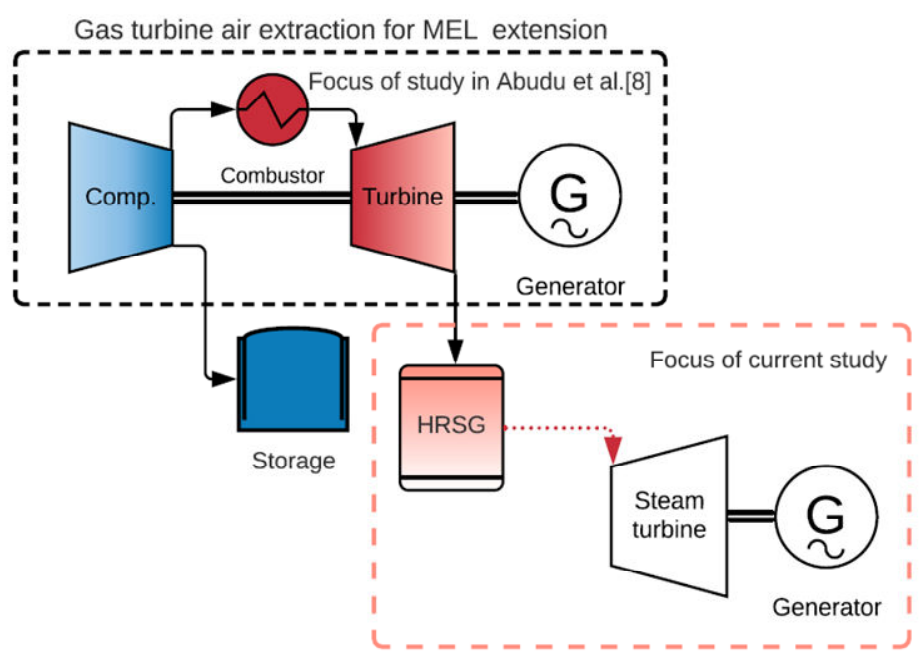

Figure 4: CCGT configuration showing layout of compressor extraction 

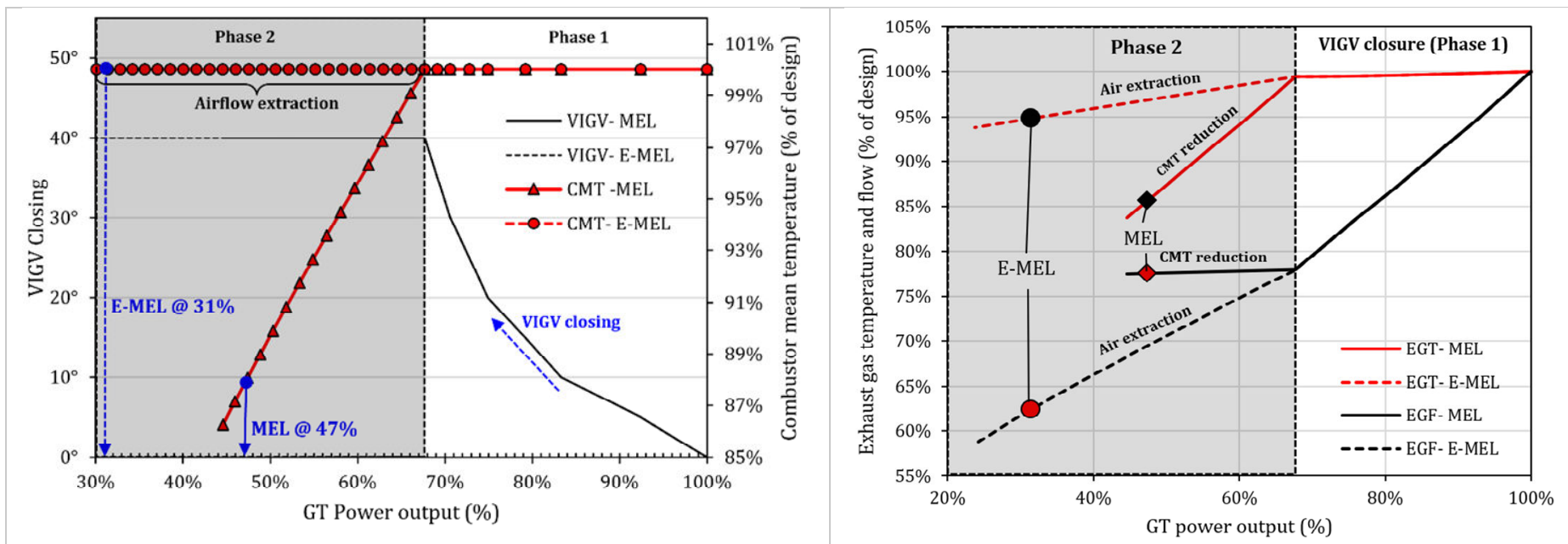

Figure 5: Effect of turndown strategies(left) on exhaust gas temperature and flow(right)

Figure 6 A-D show the resulting steam temperatures, flows, pressures, and steam turbine power outputs respectively, for the MEL and E-MEL. Each plot is segmented into the two phases described previously. As expected, similar steam conditions are observed in the first phases of the turndown strategies involving VIGV closure. Subsequently, in phase two, the steam conditions diverge. For inlet steam temperatures in the MEL case, a rapid reduction is observed for the HP steam. This is caused by a higher drop in the EGT as shown in Figure 5. For the E-MEL with air extraction, though the EGT drops relatively less, the HP steam temperature remains constant resulting from the difference with the EGT that is limited to $20^{\circ} \mathrm{C}$. This limit is exceeded in the MEL case and contributes to the drop observed in HP steam temperatures that changes at the same rate as the EGT.

For the IPT and LPT in the MEL case, there is a rise in the steam temperature in phase two. This is caused by the faster reduction in gas temperature (EGT) that further reduces the heat exchange above the HP evaporator pinch point. The effect, in turn, causes a significant reduction in HPT steam flow (top-right of the Figure 6) that reduces the heat exchange below the pinch point, faster. With a minor reduction in HP evaporator exit temperature and almost constant EGF (phase two), the flue gas at the exit of the HRSG HP section slightly increases, therefore raising the IP and LP steam temperatures.

Similar trends are observed for the inlet steam flows and pressures. This strong correlation stems from the Stodola constant that assumes all steam turbines are choked. Nonetheless, lower values of steam flow are noticed in phase two of the MEL case in comparison to the E-MEL. This effect is primarily due to the lower EGT for the former. The HP section is mostly affected as it incurs the largest reduction in temperature (from Figure 6A) in comparison to the IP and LP. The variation of 
steam properties results in the power output reduction observed in Figure 6D. The trends are consistent for both turndown strategies during VIGV closure in phase one, with the LPT power output reducing at a faster rate than the IPT and HPT. This occurs because of the cumulative effect of flow and pressure reduction on the LPT, which causes its exit enthalpy to increase faster in comparison to the IP and HP sections.

After the VIGV closure - phase two, the HPT, IPT and LPT power output drop at a much faster rate for the MEL case. The E-MEL shows a consistent reduction in power output for all steam turbines across the turndown. From the figure, it can be deduced that a higher cumulative steam power output is observed for the E-MEL case with air extraction, than design MEL case.

The performance of the CCGT and steam cycle is shown in Figure 7, which highlights the effects for both turndown cases. Similar reductions in power output and efficiency are observed during phase one - VIGV closure. In phase two, it can be observed that when the GT achieves its design MEL of 47\% power, the steam turbine is at $50 \%$ of its corresponding design power output. For the E-MEL case with a lower output of $31 \%$ of the rated load, the steam turbine generates $53 \%$ of its design. It, therefore, signifies that the power reductions in the GT from MEL turndown to E-MEL cause an increase in the power output of the steam turbine, contrary to the direction of change required for turndown. In other words, the 34\% MEL extension on the GT leads to a $6 \%$ higher steam turbine power output. This is attributed to the higher EGT causing more steam flows in the E-MEL case and subsequently leads to the elevated steam temperature in the HPT turbine.

As such, the CCGT power output does not reduce at the same magnitude of which the GT reduces. The lesser reduction in steam turbine power output limits the potential for higher MEL reduction. Figure 7 shows that the E-MEL for the CCGT becomes 39\%, which is a 19\% reduction from the CCGT MEL. The figure also presents the CCGT efficiency during the turndown strategy. It can be observed that the E-MEL is achieved at the expense of reduced thermal efficiency of the CCGT with a $25 \%$ penalty. 


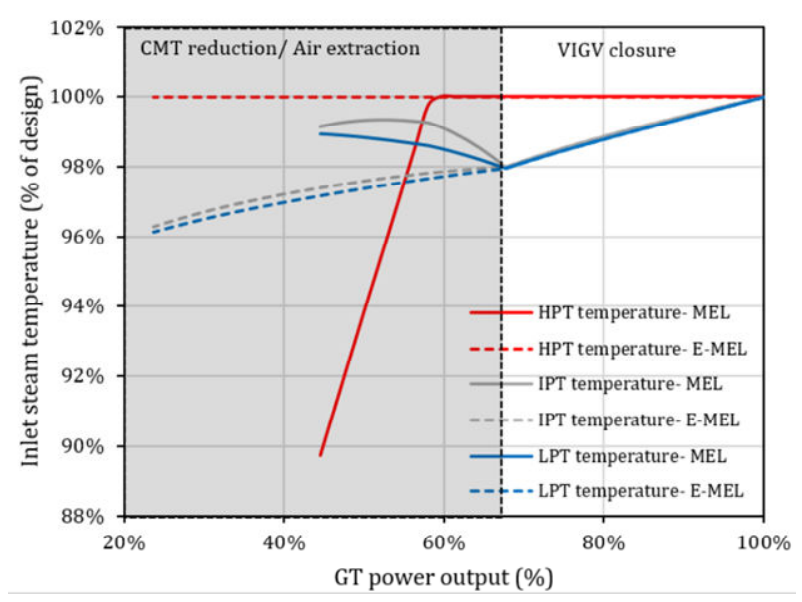

A. Inlet steam temperatures

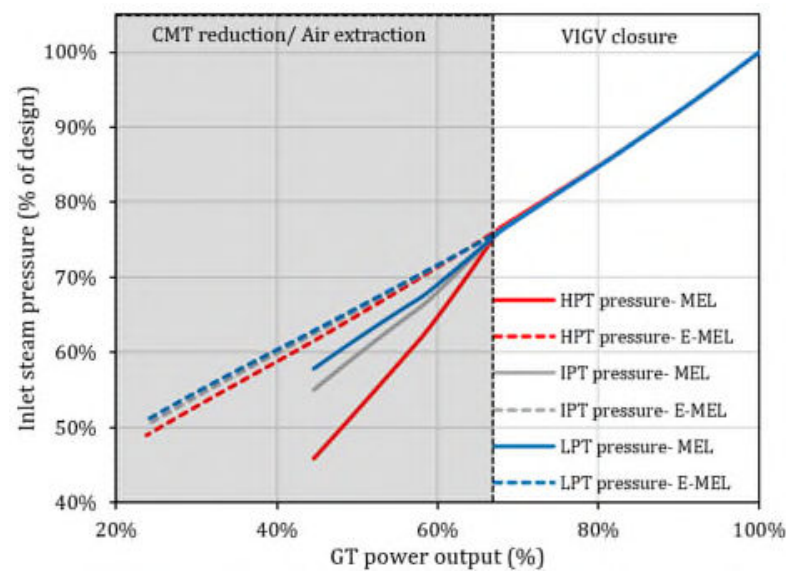

C. Inlet steam pressure

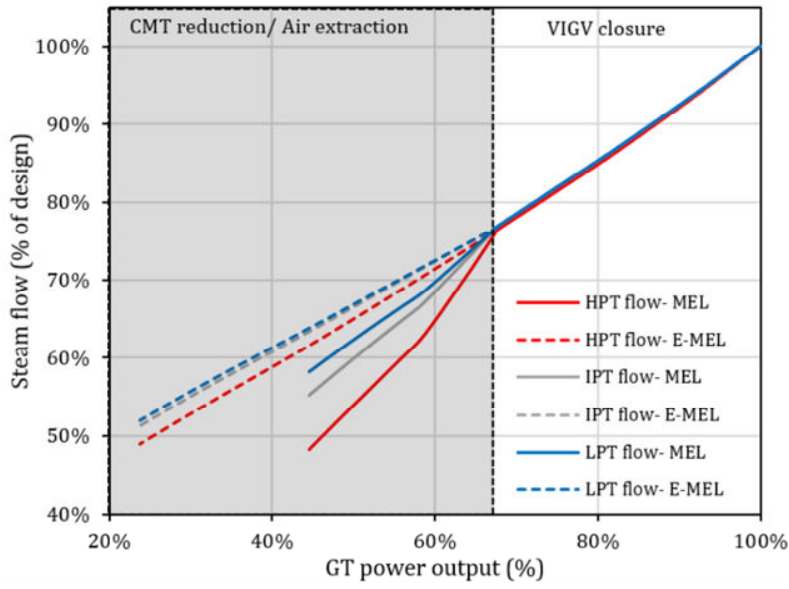

B. Inlet steam flow

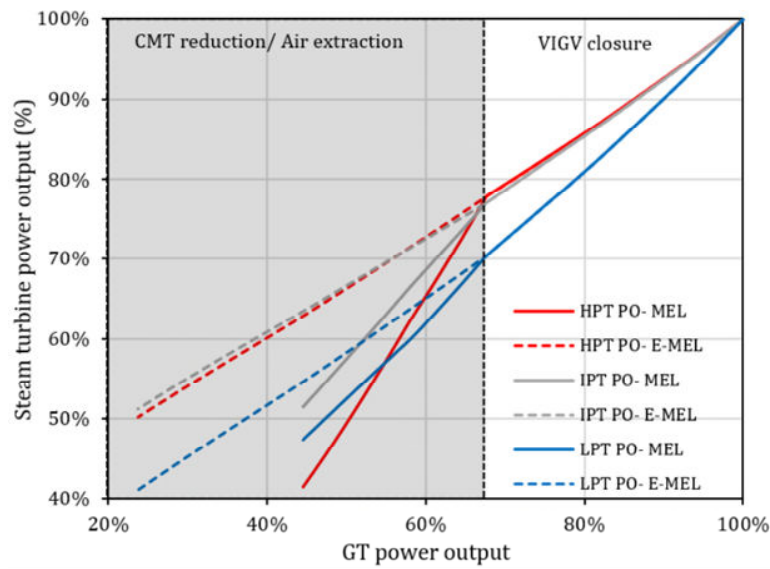

D. Steam turbine power output

Figure 6: Effect of turndowns on steam condition and steam turbine operation

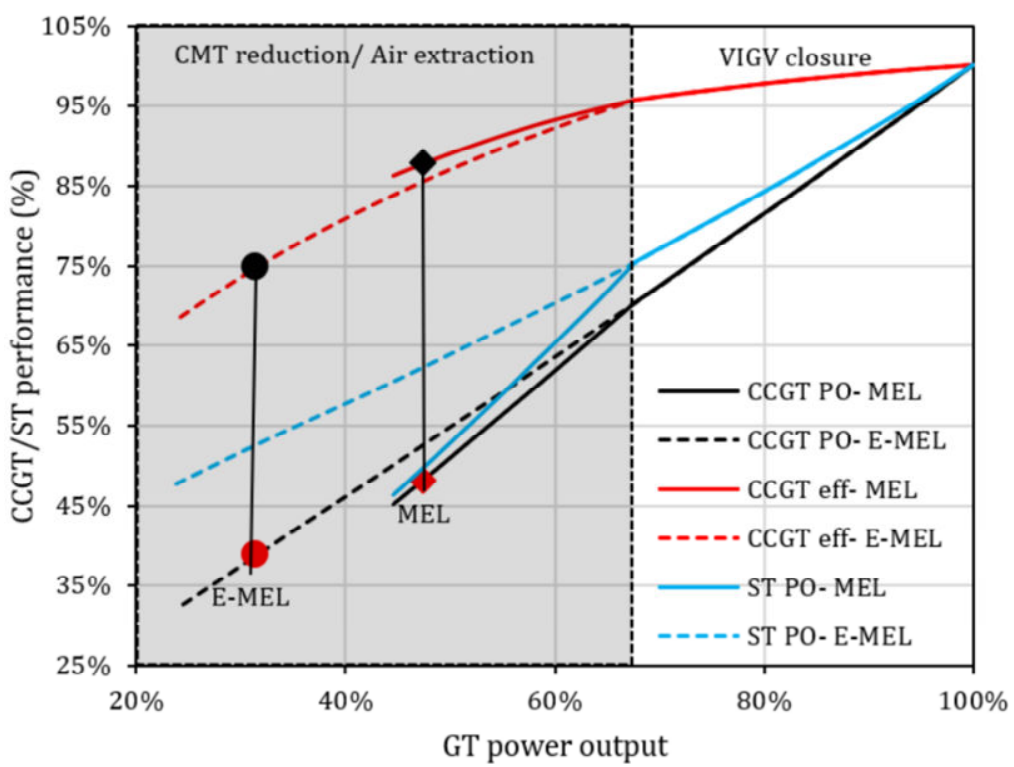

Figure 7: Effect of turndown strategy on CCGT performance 


\section{Simple cost-benefit of E-MEL}

To demonstrate the financial benefit of E-MEL, a load-following case study was conducted to highlight the additional cost-benefit in relation to the MEL. This does not consider the monetary gains from spinning reserves that also increases the position of the plant on the dispatch order. The analysis uses data on power generation from wind and solar sources for a year (2019) to represent relative grid power fluctuations [2]. The data is segmented into seasons and normalized by the maximum generation of each season. From the normalized combined wind and solar generation schedule, a short-fall has been established based on the design power output of the CCGT plant. From the figure, the CGGT output fluctuates to compensate for the difference between $285 \mathrm{MW}$ and renewable power generation. To account for CCGT-MEL and CCGT-E-MEL effects, the resulting CCGT generation schedule is modified by limiting the minimum generation to $48 \%$ for the former, and $39 \%$ for the latter. These are based on the minimum load shown previously. Figure 8 shows the power generation schedules for both cases, within 48 hours in the winter. It also shows that in the E-MEL operation, the CCGT can come online sooner and longer, given that the minimum allowable power (determined by GT emissions) is lower than the CCGT-MEL case. This results in more energy produced in the E-MEL case; hence better backup-up ability, defined here as the portion of CCGT energy produced in relation to the short-fall of the renewable generation.

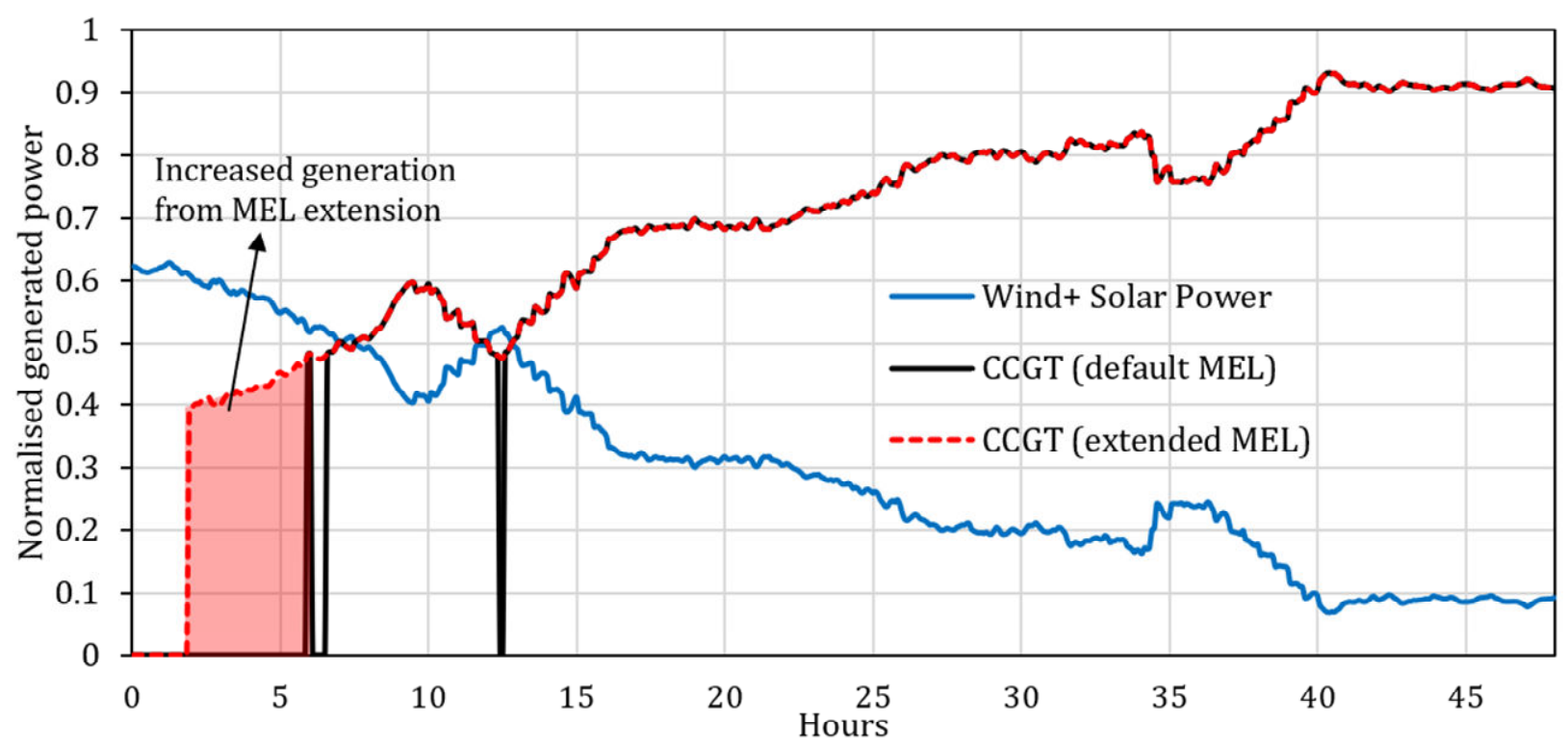

Figure 8: Power generation schedules for CCGT-MEL and CCGT-E-MEL

Table 3 shows the differences between both cases for different seasons indicating that more CCGT generation in the summer, arising from the fluctuations in the renewable generation.

Simple calculations have been conducted to highlight the increased cost-benefit of the E-MEL operation compared to the MEL operation. The right side of the table shows the increase in engine 
hours (EOH) and energy as a percentage. The additional revenue was calculated by multiplying the increased energy by the average cost of electricity in 2019 that is $£ 43.7$ per MWh [16]. This amounts to additional revenue of $£ 5.8$ million in that year. However, this does not consider the capital investment in a storage system or retrofit of the GT engine. In such a case, the cumulative revenue increase across the life span of the storage system is to be benchmarked against the capital cost and maintenance.

Table 3: Cost-benefit of turndowns by the seasons of the year

\begin{tabular}{|c|c|c|c|c|c|c|c|c|c|}
\hline & \multicolumn{3}{|c|}{ CCGT MEL } & \multicolumn{3}{|c|}{ CCGT E-MEL } & \multirow[b]{2}{*}{$\begin{array}{c}\text { Increase } \\
\text { in EOH } \\
(\%)\end{array}$} & \multirow[b]{2}{*}{$\begin{array}{c}\text { Increase in } \\
\text { generation } \\
(\%)\end{array}$} & \multirow[b]{2}{*}{$\begin{array}{l}\text { Additional } \\
\text { revenue }\end{array}$} \\
\hline Seasons & EOH & $\begin{array}{c}\text { Energy } \\
\text { generated } \\
\text { (MWh) }\end{array}$ & $\begin{array}{c}\text { Back-up } \\
\text { ability }\end{array}$ & EOH & $\begin{array}{c}\text { Energy } \\
\text { generated } \\
\text { (MWh) }\end{array}$ & $\begin{array}{c}\text { Back-up } \\
\text { ability }\end{array}$ & & & \\
\hline Winter & 1215 & 244468 & $74 \%$ & 1503 & 280090 & $84 \%$ & $24 \%$ & $15 \%$ & $£ 1,558,075$ \\
\hline Spring & 1565 & 321740 & $83 \%$ & 1842 & 356050 & $92 \%$ & $18 \%$ & $11 \%$ & $£ 1,500,730$ \\
\hline Summer & 1717 & 351723 & $88 \%$ & 1944 & 380152 & $95 \%$ & $13 \%$ & $8 \%$ & $£ 1,243,516$ \\
\hline Autumn & 1635 & 317564 & $84.80 \%$ & 1907 & 351538 & $94 \%$ & $17 \%$ & $11 \%$ & $£ 1,486,021$ \\
\hline $\begin{array}{c}\text { Year } \\
(2019)\end{array}$ & 6132 & 1235494 & $82 \%$ & 7197 & 1367829 & $91 \%$ & $17 \%$ & $11 \%$ & $£ 5,788,341$ \\
\hline
\end{tabular}

\section{CCGT Ramp rate improvements with airflow injection}

The potential to improve the ramp-up rate of a GT using airflow injection has been shown in transient simulations of Abudu et al [12]. This is depicted at the top of Figure 9 that shows the injection location at the back end of the compressor. For air injection in the referred study, it was assumed that the source could be from an auxiliary compressor with a higher discharge pressure than the GT compressor exit. The alternative is a pressurised storage system as shown. This section focuses on the ramp-up rate improvement that is attributed to air injection for a CCGT. The bottoming cycle plant benefits from an increase in exhaust gas flow that improves the exhaust heat flux during the ramp-up. Figure 10 shows the GT exhaust flow and temperature schedule caused by the ramp-up rate of the topping cycle. This schedule is categorised by the initial segment on the left that involves increasing the combustor mean temperature (CMT) and the second segment on the right, in which the VIGV is gradually opening. For the design ramp-up scenario (without air injection), the increase in CMT increases the EGT until the design CMT is reached at 196 seconds. This is followed by the opening of the VIGV that increases the power, also increasing the engine EGF, until the maximum rated power is achieved. The default ramp-up schedule mentioned amounts to an engine ramp-up rate of $12 \mathrm{MW} / \mathrm{min}$; this is also consistent with the manufacturer specification [15] and it applies to both segments of the operation. 


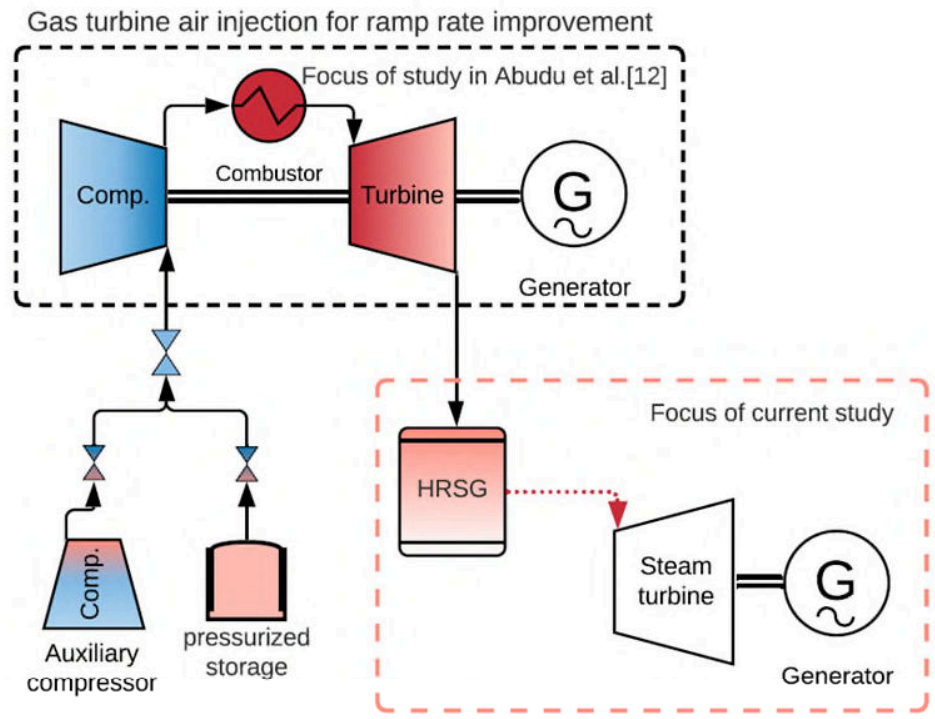

\section{Figure 9: CCGT configuration showing layout of compressor injection}

Different cases of air injection are shown; these range from $2 \%$ to $10 \%$ (of compressor discharge flow) maximum air injection for the respective cases. In the case of $2 \%$ maximum injection, there is a gradual increase in the compressed air for the first 15 seconds before $2 \%$ is reached. Beyond this point, the $2 \%$ injection is maintained to the end of the ramp-up at 496 seconds. This applies to other cases: $4 \%, 6 \%, 8 \%$ and $10 \%$ for which the maximum values are reached at $29,44,60$ and 83 seconds, respectively.

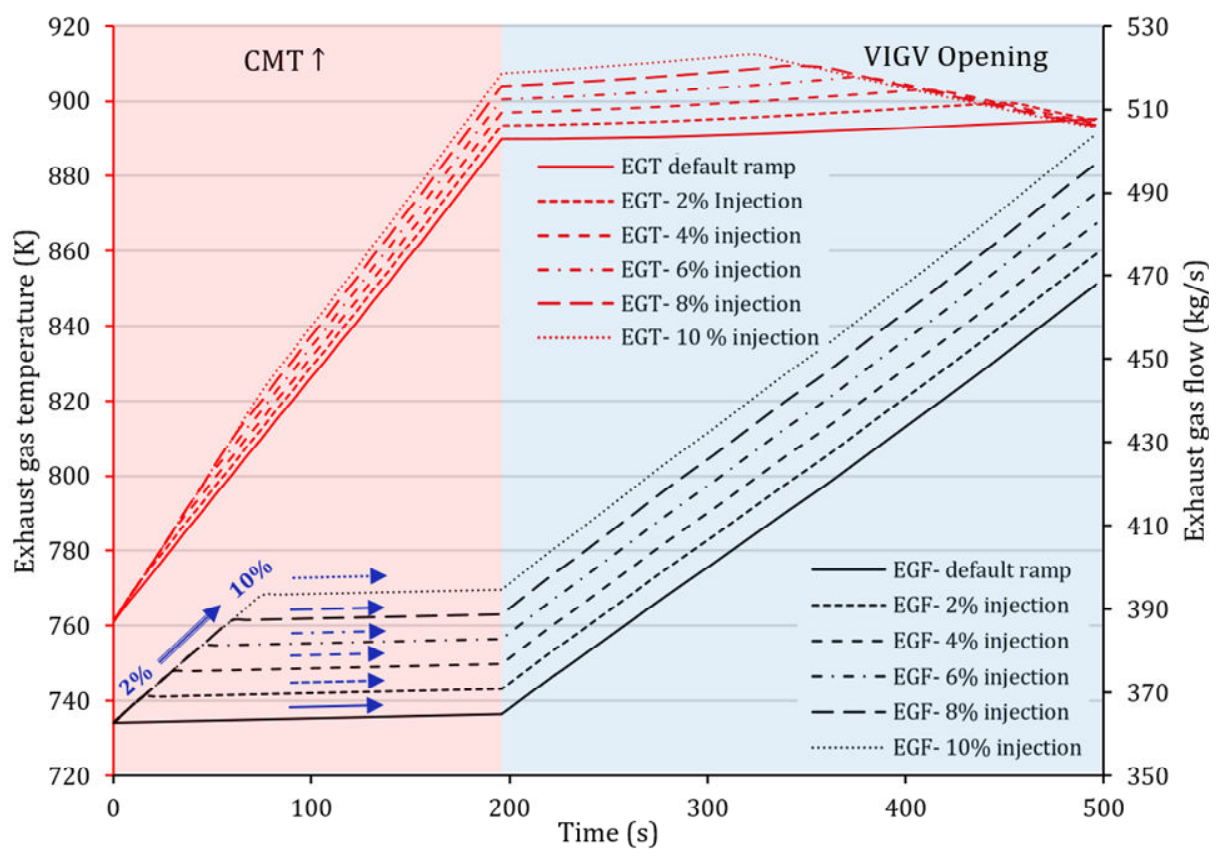

Figure 10: Effect of air injection on exhaust gas during the ramp-up 
For the injection cases, similar trends are observed for the EGT and EGF, although with higher absolute values for increasing injection quantities. These variations in exhaust parameters modify the exhaust heat flux and as such, the bottoming cycle performance.

The steam conditions for the design ramp-up and the highest injection case $10 \%$ is shown in Figure 11. It presents the temperatures, pressures, and flows of steam as the engine ramps-up to full load. Each plot is also segmented to show the effect of CMT changes and followed by the VIGV opening, on the steam conditions. The plots on the right-hand side indicate the variation of steam properties for the $10 \%$ airflow injection case. The bar shown on these plots indicate when the full load of the CCGT plant is achieved. It should be noted that during injection operation, the full load point is reached before the full opening of the VIGV. From the figure, similar trends are observed for the design and injection cases in the HP steam conditions plot. The maximum steam temperature is achieved earlier for the injection scenario at 91 seconds, as opposed to 115 seconds for the design case. This increase also applies to the HP flow and pressure.

For the IP steam conditions for both cases, a reduction in steam temperature is observed in the first segment. The second segment shows an increase in the steam temperature that is accompanied with increment in pressure and flow. As previously explained, this is due to the variation in HP economiser gas outlet temperature that reduces in the first segment and increases in the second as the rate of rise of HP steam flow is altered. The corresponding injection ramp-up conditions show an increase in IP steam temperature at the start of the ramp-up, until the maximum injection rate of $10 \%$ is achieved at $75 \mathrm{~s}$. Afterwards, the steam temperature reduces like the design case, and increases after the maximum CMT is achieved. The reduction in IP steam temperature originates from higher rate of rise in heat exchanged below the pinch point of the HRSG HP section in comparison to the gas temperature at the HP economizer exit. This in turn results from the rise in CMT with an almost constant gas flow.

For the LP steam temperature, like the IP temperature, reductions and increments are observed during CMT increase and VIGV opening respectively. Similarly, an increase is noticed for the injection case, as the injection quantities increase, although milder than that observed for the IP steam temperature. Comparable trends can be noticed for the flow and pressure across the pressure levels between the design and injection ramp-up. Although, the injection ramp-up trends appears like a compressed version of the design scenario. 

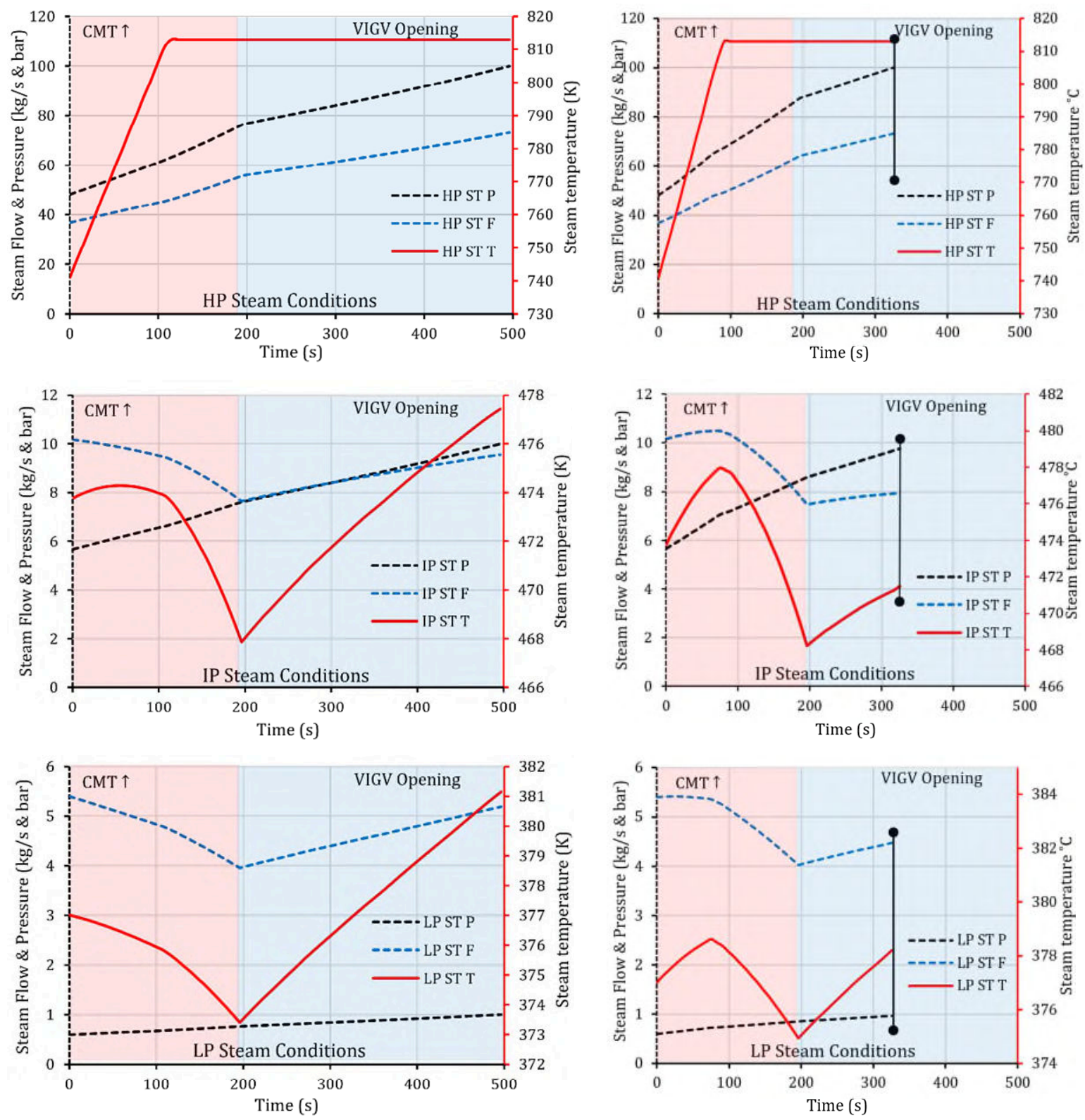

Design ramp-up

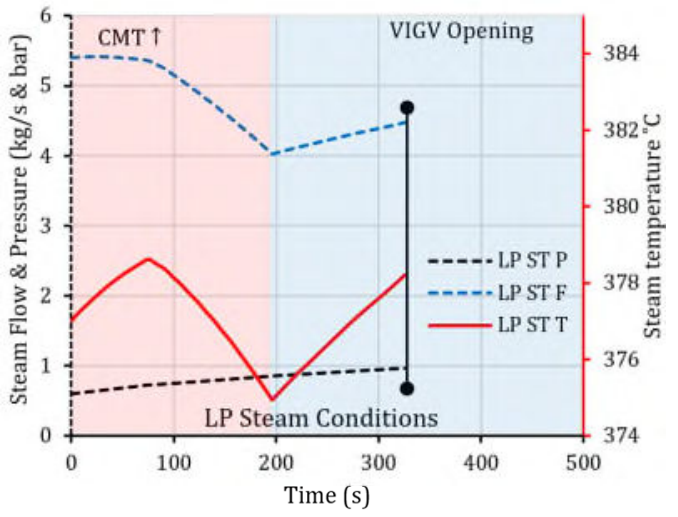

$10 \%$ injection ramp-up

\section{Figure 11: Effect of air injection ramp-up on steam condition}

Figure 12 indicates the performance parameters of the design ramp-up (fig. 12A) and the air injection case with the $10 \%$ injection scenario (fig. 12B). The power outputs and efficiencies of the GT, steam turbine and CCGT for the design case shows the improvements of these parameters with time, that is influenced by the GT increased temperature and flow. The final values at 496 seconds are consistent with the design point performance of the engine and CCGT plant. The ramp-up for the steam turbine and CCGT shows an almost linear progression that is altered at the onset of VIGV 
opening. For the GT, the ramp rate is fixed to match with the specified design requirement. The thermal efficiency of the steam turbine increases, arising from the GT EGT and EGF in Figure 10. The increase in EGT raises the HRSG inlet temperature and specific heat of the flue gas that is accompanied with EGF rise. Equation 13 shows these parameters in the denominator, indicating that the total steam power output (influenced mainly by the amount of steam produced), increases faster than these inputs. The CCGT efficiency also increases, resulting from the increase in the steam power as expressed in Equation 11. For the injection scenario in fig.15B, a significant increase in power outputs and efficiencies is observed at the start of the ramp-up that coincides with the increase in injection percentage. After the maximum injection is achieved, a slower rate of increase is observed across the performance parameters. However, the steam cycle efficiency shows an almost linear increase during CMT rise that is independent of the injection rate increase. The full power of the GT and CCGT is achieved sooner, at 328 seconds as highlighted with the bar. This indicates the end of the ramp-up improvement from airflow injection. It can also be observed from the figure that this full power is achieved at a higher efficiency in comparison to the design case on the left.

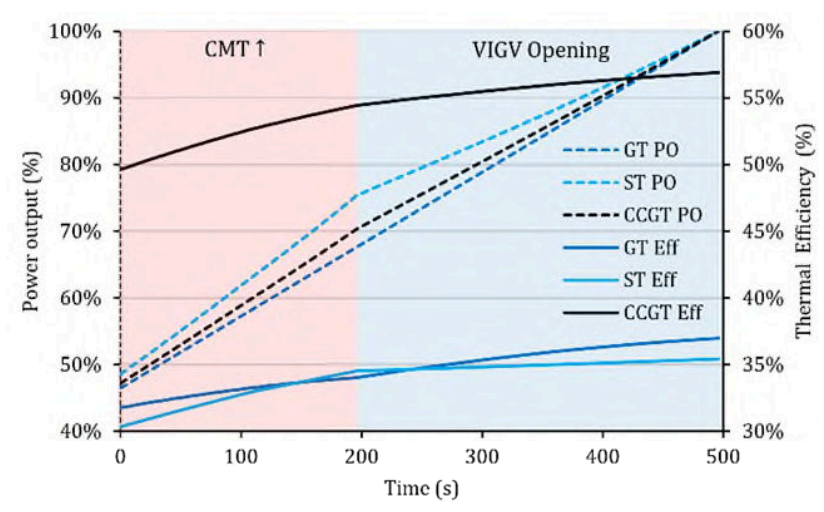

A. Design Ramp-up

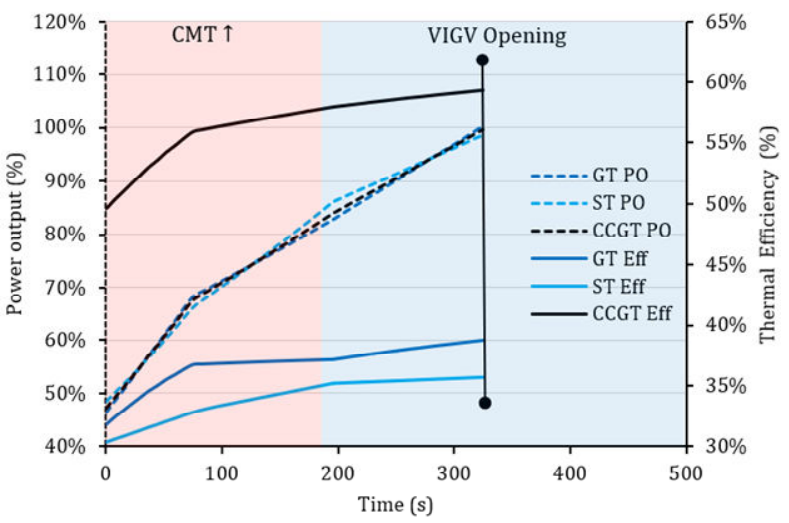

B. $10 \%$ Injection ramp-up

Figure 12: Effect of air injection ramp-up on the steam turbine and CCGT performance

The CCGT power output schedules for the other injection rates considered are provided in Figure 13. The figure highlights the time required to attain the full power of the plant with airflow injection for the individual ramp-up cases. The injection ramp-ups are mostly enhanced by the increase in injection rate that occurs at the onset of the ramp-up. 


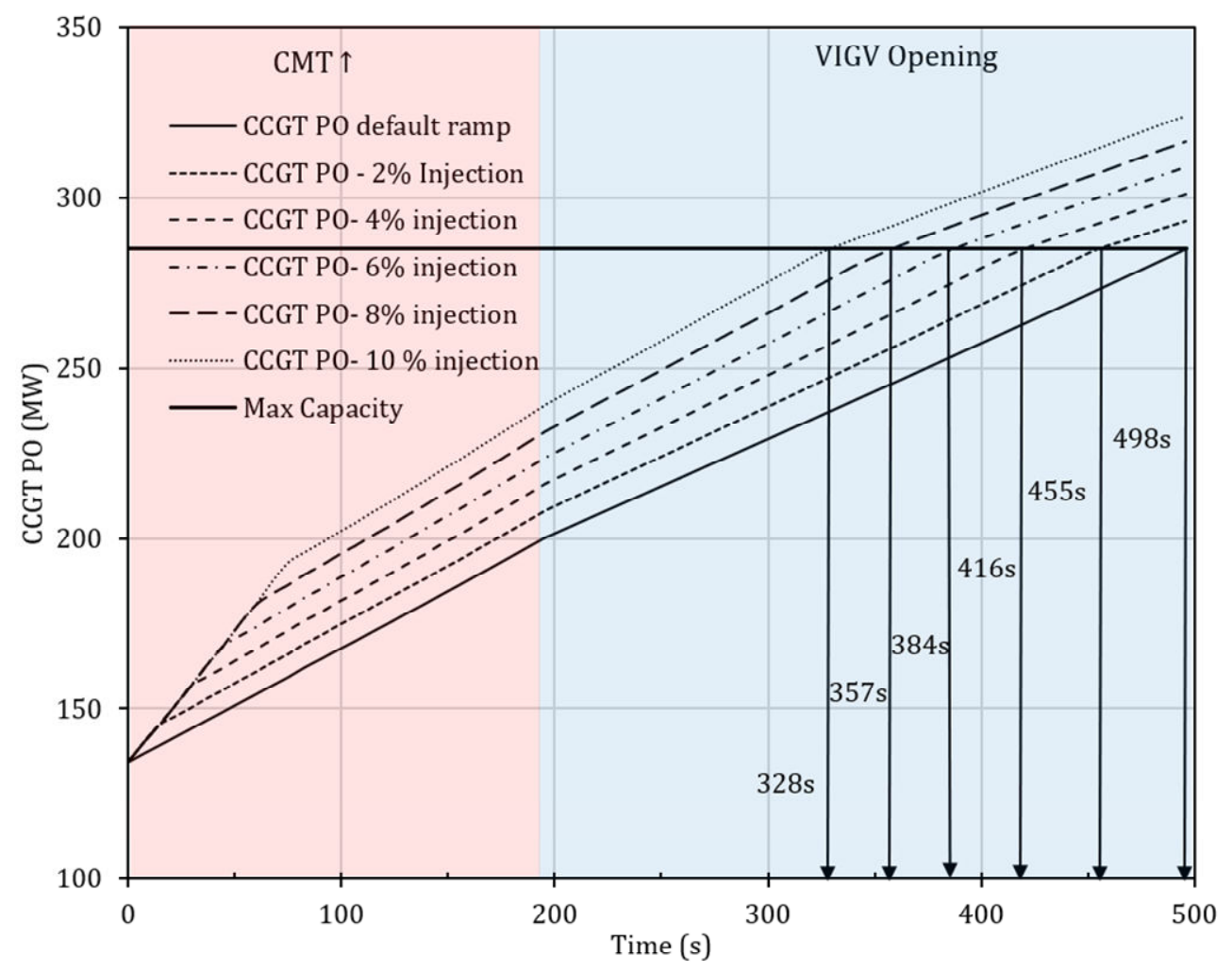

Figure 13: CCGT power output schedule for design and injection ramp-up

To quantify the flexibility benefits of injection, the improved ramp rates of the engine are computed using Equation 15. The equation relates the power output difference to the duration required to achieve the full power at the design point. The resulting ramp rates and percentage improvements are provided in Figure 14, which compares the ST, GT and CCGT benefits. Ramp rates of up to $27 \mathrm{MW} / \mathrm{min}$ are achievable with $10 \%$ airflow injection into the GT of a CCGT. This translates to a $51 \%$ increase in the ramp rate of the combined cycle engine. A consistent increase in improvements is observed across the injection rate considered. For every $2 \%$ increment in flow injection, the ramp rate is seen to improve by approximately $10 \%$. It should be noted that while the absolute ramp rates for the CCGT are higher, higher ramp rates benefits are achieved for the standalone GT. This is due to the lesser improvements for the steam turbine ramp rate that reduces the overall benefits on the CCGT.

$$
\text { Ramp rate }=\frac{\text { Rated } P O-\text { Initial } P O}{\text { time at rated } P O-\text { time at initial } P O}
$$




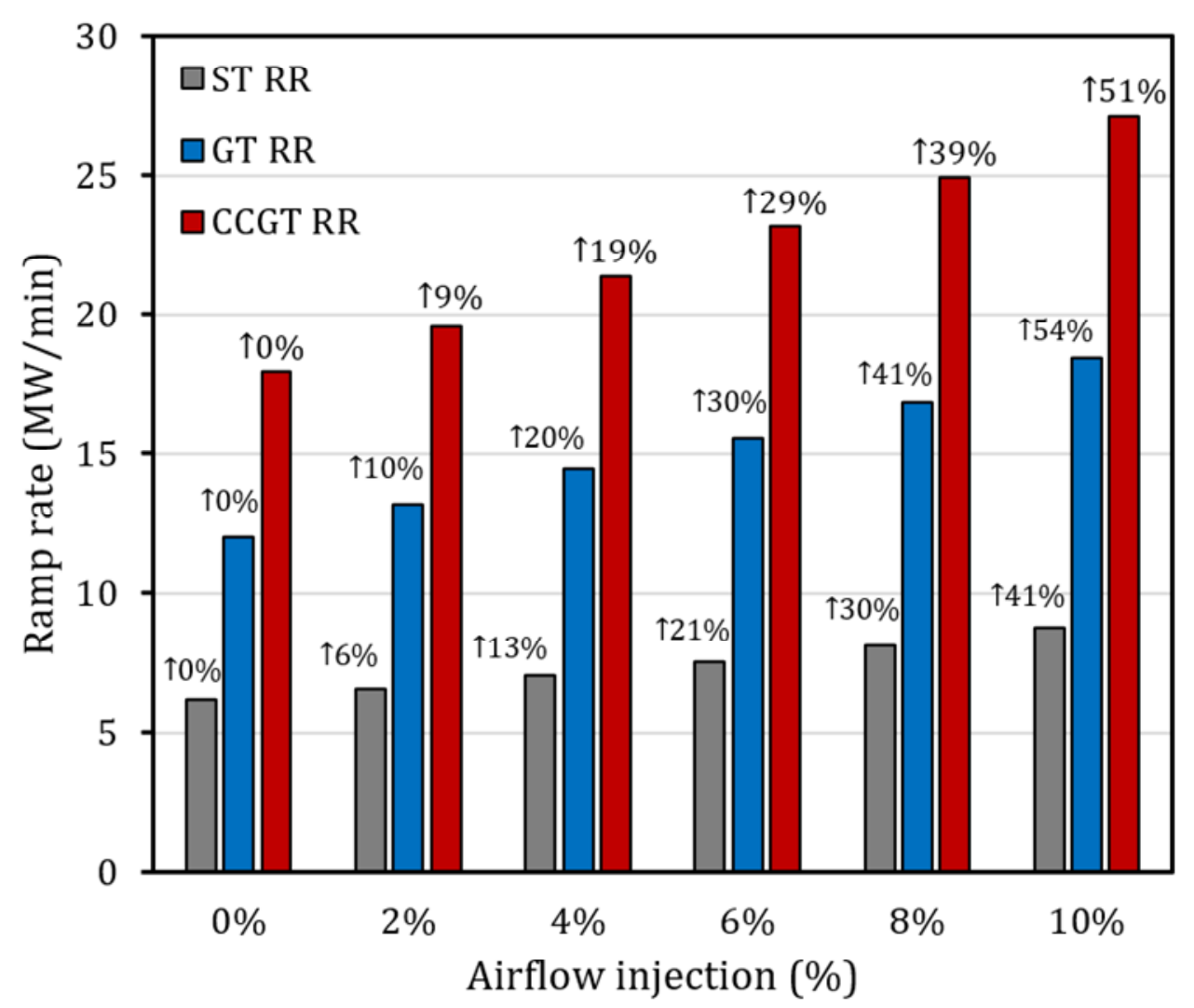

Figure 14: CCGT and GT ramp rate benefits from airflow injection

In comparison to conventional methods of ramp rate improvements, airflow injection can achieve these benefits without overly deviating from the engine normal operation. The implication of this approach on the LPT steam quality and stack temperature is presented in Figure 15. These parameters are selected to reflect the potential operational concerns that could result in injection ramp-up. A reduction of LPT exit steam quality indicates the potential for erosion of LPT blades, while a reduction in stack temperature can cause corrosion of heat exchanger components. Figure 15a shows the variation in the selected parameters as the CCGT ramps up to the full load. It shows an increase in steam quality, at the beginning of the ramp-up that reduces after the maximum HP steam temperature is achieved. This is due to the entropy variation across the exit of the steam turbines that define the exit enthalpy and as a result steam quality. A slower rate of reduction is observed during VIGV opening in comparison to the CMT increase segment, as the steam temperature is fixed and the rate of rise in pressure reduces. The stack temperature is seen to reduce rapidly in the first segment of the ramp-up and increase slightly afterwards. This effect is due to the faster rate of increase in the gas temperature drop across the LP economizer in comparison to the rate of increase in EGT. For the injection ramp-up in Figure 15b, a similar trend is observed, with a slower rate of 
steam quality increase at the beginning of the ramp-up. A reduced peak value is also noticed for the injection case. Like the design case, the stack temperature reduces to a lower value during CMT increase and returns to the design value at full power. These small variations noticed infer no concern for erosion or corrosion, associated with injection ramp-up in these conditions.

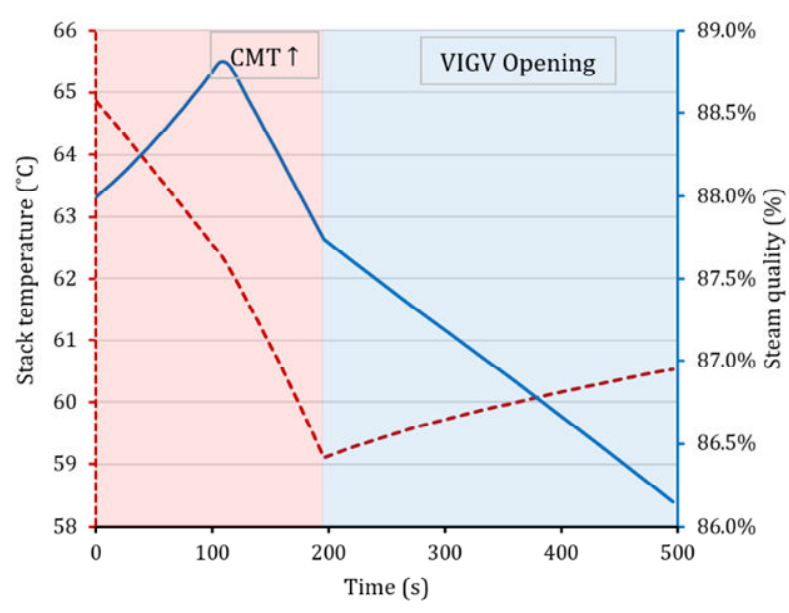

A. Design ramp-up

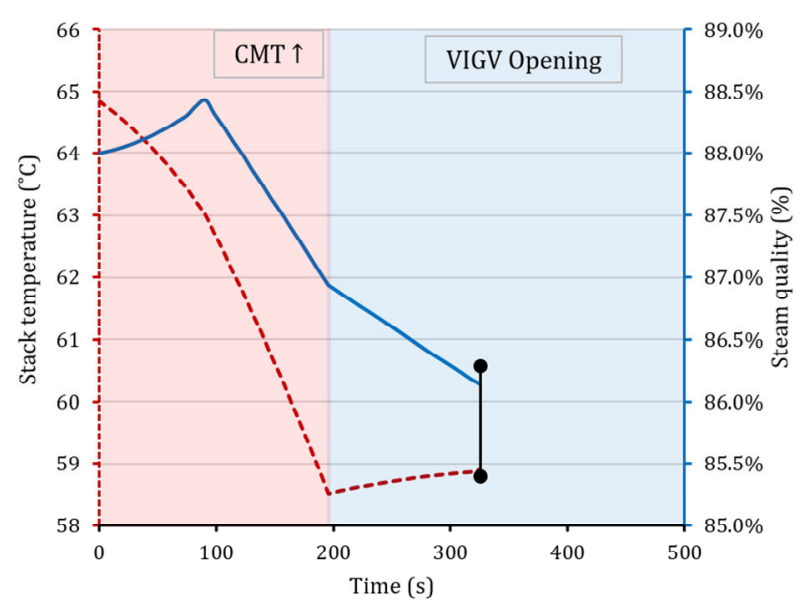

B. $10 \%$ Injection ramp-up

Figure 15: LPT exit steam quality and stack temperature for design and injection ramp-up

\section{Power augmentation}

Discrete injection rates of airflow were considered for power augmentation at the design full load. Unlike the cases for the transient operation to improve the ramp-up rates, these individual injections are conducted to boost the engine power output above the full load. Figure A1 to A3 of Appendix A show the changes in exhaust/flue gas conditions, that of the HRSG steam, power outputs and efficiencies. The changes show a similar variation of parameters as in the transient simulations, with $20 \%$ and $8 \%$ rise in power output and efficiency of the CCGT, respectively at the highest injection rate of 15\%. The observed significant increase in pressures in Figs. A2 could pose an operational limit with regards mechanical integrity. Although, the use of a once-through HRSG could lessens this concern.

\section{Conclusion}

The study has focused on the implications of improved GT flexibility through air extraction and injections on the bottoming cycle of a CCGT plant. These two processes have been considered independently; air extraction (for storage) relates to the MEL extension of the plant, while air 
injection (from higher pressurised energy storage or auxiliary compressor) applies to the ramp-up rate improvement.

\section{MEL extension}

Compressor air extraction on the GT:

- changes the exhaust conditions that alter the steam conditions of the bottoming cycle. The steam power output reduces, as opposed to a reduction in the GT. This lower load is favourable for improved MEL as obtained in the GT; however, the corresponding drop in the steam turbine power output is lesser, resulting from the increase in the exhaust gas temperature at low power setting. This brings about a 19\% improvement (decrease) of the CCGT MEL as opposed to 34\% for the stand-alone GT engine. The improvement in CCGT MEL amounted to $25 \%$ reduction in thermal efficiency; for the GT, it is $40 \%$.

- can improve the backup-up ability of the CCGT plant as shown in the case study presented for load-following operation with renewable power generation. This brought about a $25 \%$ increase in the engine hours of operation in the winter month, in comparison with the design MEL case. The simple cost-benefit analysis shows a $£ 5$ million increase in revenue for the plant in the total period considered.

\section{Ramp-up rate improvement}

Compressor air injection on the GT:

- varies the steam conditions of the HRSG during ramp-up. This increases the ramp-up rate for the steam turbine by $41 \%$, however lower than the GT engine. As a result, the overall CCGT ramp-rate improved by $51 \%(40 \mathrm{MW} / \mathrm{min})$ when the stand-alone GT achieves a $54 \%$ increase.

- resulted in minor deviations in stack temperature and LP steam exit quality in comparison to the design ramp-up. This reduces the concern for the erosion of steam LPT blades and corrosion of HRSG components from improved ramp-up.

The study has shown the importance of considering the bottoming cycle in GT upgrades. It demonstrates that the flexibility gains for the stand-alone GT topping cycle are more optimistic than when the bottoming cycle (hence CCGT plant) is accounted for. The analysis presented considers the most crucial aspect of the CCGT thermodynamics. However, it should be noted that the mechanical and control constraints are not considered here. As well, the implications of steam drum size and piping have not been considered but are expected to result in more optimistic benefits for MEL 
extension and pessimistic ones for ramp rates improvements. For the MEL extension, there can be a further improvement if the HP steam can be lowered. With regards to ramp-up rate improvement, the potential for increased thermal transient on the steam HPT blades could limit the injection rate considered.

\section{Acknowledgement}

This study is part of TURBO-REFLEX project that has received funding from the European Union's Horizon 2020 research and innovation programme, under grant agreement No. 764545.

$\begin{array}{ll}\text { Nomenclature } \\ \text { 1-4 } & \text { Points on Cycle- Flue Gas Side } \\ \text { A-E } & \text { Points on Cycle- Steam Side } \\ \text { a-d } & \text { Constants } \\ \text { ACAES } & \text { Adiabatic Compressed Air Energy Storage } \\ \text { BESS } & \text { Battery Energy Storage System } \\ \text { BOV } & \text { Blow Off Valve } \\ \text { CCGT } & \text { Combined Cycle Gas Turbine } \\ \text { CMT } & \text { Combustor Mean Temperature } \\ \text { CO } & \text { Carbon Monoxide } \\ \text { Cp } & \text { Specific Heat Capacity } \\ \text { EGF } & \text { Exhaust Gas Flow } \\ \text { EGT } & \text { Exhaust Gas Temperature } \\ \text { E-MEL } & \text { Extended Minimum Environmental Load } \\ \text { EOH } & \text { Engine Operating Hours } \\ \text { GB } & \text { Great Britain } \\ \text { GT } & \text { Gas Turbine } \\ \text { h } & \text { Enthalpy, Joules } \\ \text { HP } & \text { High Pressure } \\ \text { HPT } & \text { High Pressure Turbine- Steam } \\ \text { HRSG } & \text { Heat Recovery Steam Generator } \\ \text { IPT } & \text { Intermediate Pressure Turbine- Steam } \\ \text { ISO } & \text { International Organization for Standardization } \\ \text { LHV } & \text { Lower Heating Value } \\ \text { LLCO } & \text { Low Load Carbon Monoxide } \\ \text { LPT } & \text { Lop Pressure Turbine- Steam } \\ \text { MEL } & \text { Minimum Environmental Load } \\ \text { OEM } & \text { Original Equipment Manufacturer } \\ \text { P } & \text { Pressure, Bars } \\ \text { PO } & \text { Power Output, MW } \\ \text { PO } & \text { Power Output, MW } \\ & \end{array}$


Q Heat Energy, KJ

SWM Stadtwerke München

$\mathrm{T} \quad$ Temperature, $\mathrm{K}$

VIGV Variable Inlet Guide Vanes

W Flow, Kg/S

\section{Subscripts}

0 Turbine exit

a Approach Point

amb ambient

cc Combined Cycle

d Discharge

g Exhaust Gas

GT Gas Turbine

HRSG Heat Recovery Steam Generator

is Isentropic

p Pinch Point

R Rankine Cycle

s Steam

sat Saturation

ST Steam Turbine

\section{Appendix A}

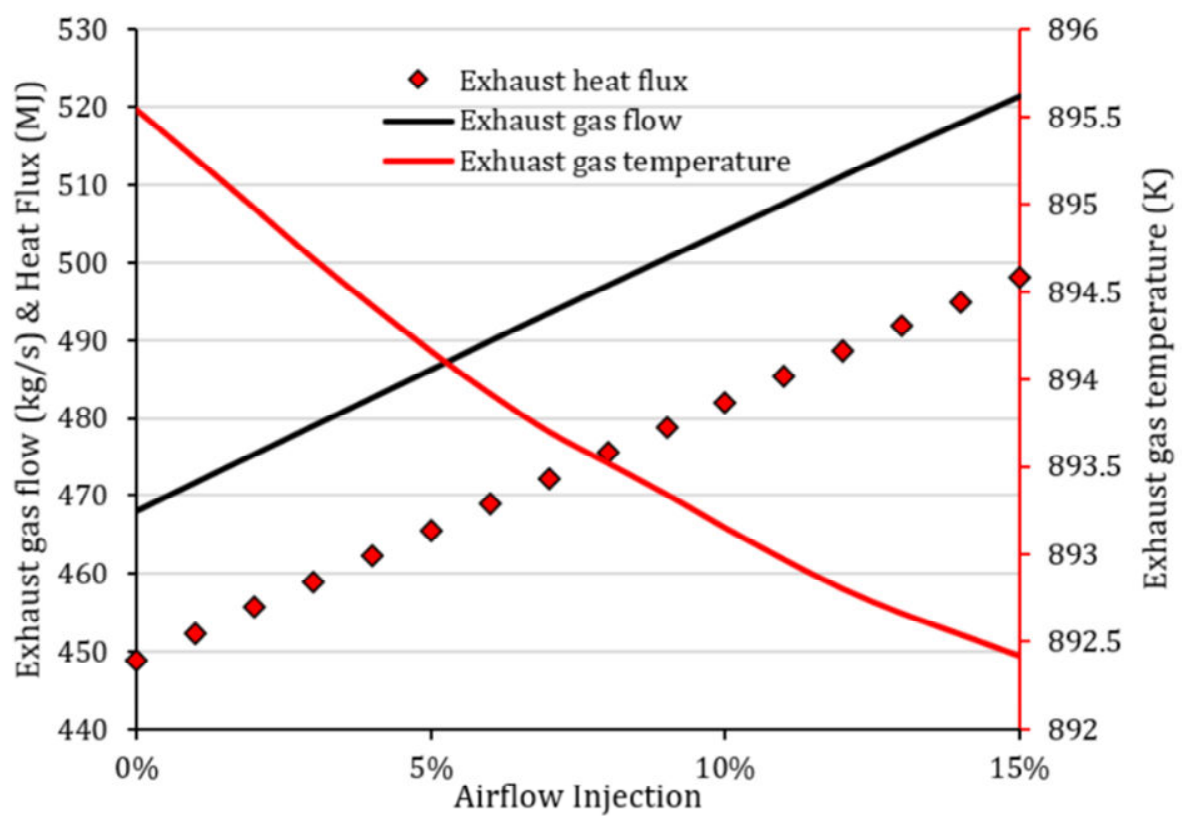

Figure A1: Effect of air GT injection on exhaust/flue gas conditions 


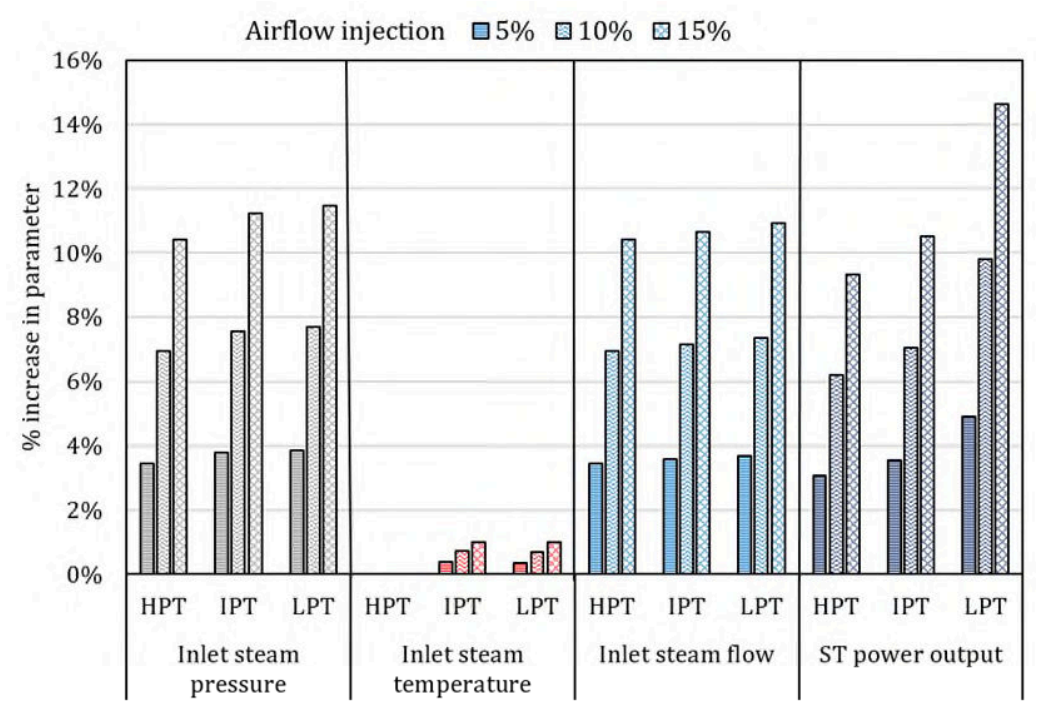

Figure A2: Effect of GT air injection on CCGT steam conditions

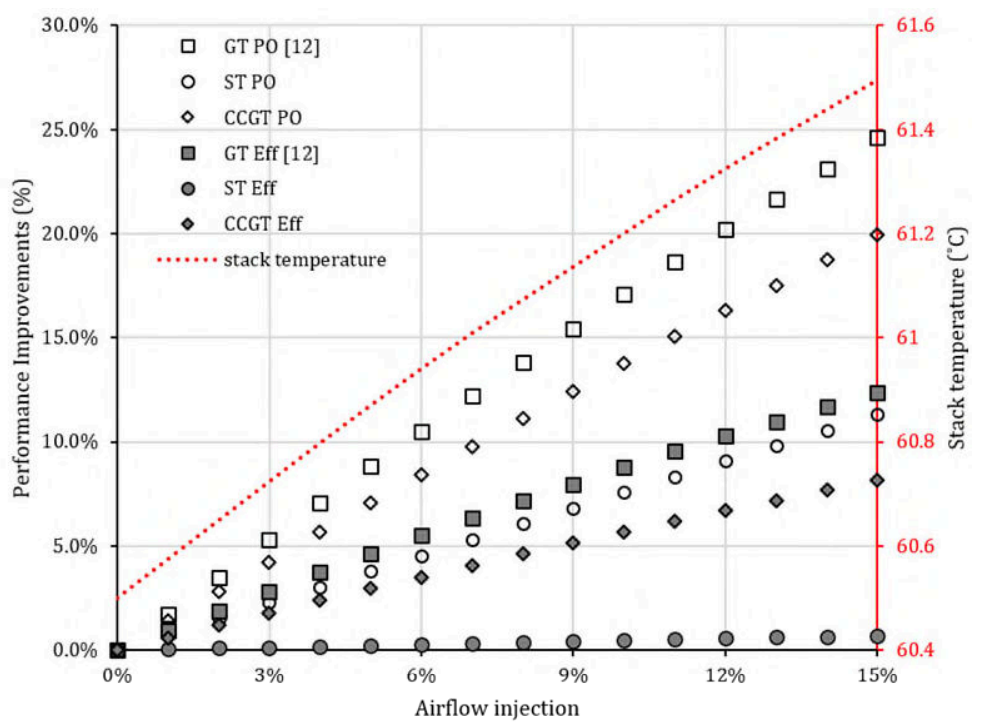

Figure A3: Performance implications of GT air injection on power output and efficiency

\section{References}

[1] U.S. Energy Information Administration, "International Energy Outlook 2019," U.S. Energy Information Administration, Washington, 2019.

[2] Gridwatch, "G.B. National Grid Status," June 2020. [Online]. Available: https://www.gridwatch.templar.co.uk/. [Accessed 15 June 2020]. 
[3] C. Ruchti, H. Olia, K. Franitza, A. Ehrsam and W. Bauver, "Combined Cycle Power Plants as ideal solution to balance grid fluctuations Fast Start-up Capabilities," in Colloquium of Power PLant Technologies, Dresden, 2011.

[4] N. Pratyush, L. David, P. Adam and R. Douglas, "Low Load Operational Flexibility for Siemens F- and G-Class Gas Turbines," in ASME Turbo Expo 2010: Power for Land, Sea, and Air, Glasgow, 2010.

[5] M. Cioffi, S. Piola, E. Puppo, A. Silingardi and F. Bonzani, "Minimum Environmental Load Reduction in Heavy Duty Gas Turbines by Bleeding Lines," in ASME Turbo Expo 2014: Turbine Technocal Conference and Exposition, Dusseldorf, 2014.

[6] D. Rouwenhorst, R. Widhopf-Fenk, J. Hermann, M. Haringer, J. Becker, J. Gerhard and J. Niedermeier, "Part-Load Limit Reduction of a Frame 9E Using a Precursor for Combustion Dynamics," in Turbo Expo: Powwer for Land, Sea, and Air, Oslo, 2018.

[7] J. D. Wojcik and J. Wang, "Feasibility study of Combined Cycle Gas Turbine (CCGT) power plant integration with Adiabatic Compressed Air Energy Storage (ACAES)," Applied Energy, vol. 221, pp. 477- 489, 2018.

[8] K. Abudu, U. Igie, O. Minervino and R. Hamilton, "Gas Turbine Minimum Environmental Load Extension with Compressed Air Extraction for Storage," Applied Thermal Engineering, 2020.

[9] L. Balling, "Fast cycling and rapid start-up: New generation of plants achieves impressive results," Modern Power Systems, vol. 31, no. 1, pp. 35-40, January 2011.

[10] J. DiCampli and D. Laing, "State of the Art Hybrid Solutions for Energy Storage for Grid Firming," GE Power, June 2017. [Online]. Available: https://www.ge.com/content/dam/gepowerpgdp/global/en_US/documents/product/hybrid/GE\%20PGE\%202017\%20Hybrid\%20paper.pdf. [Accessed August 2019].

[11] M. J. Kim and T. S. Kim, "Integration of compressed air energy storage and gas turbine to improve the ramp rates," Applied Energy, vol. 247, pp. 363-373, August 2019.

[12] K. Abudu, U. Igie, O. Monervino and R. Hamilton, "Gas Turbine Efficiency and Ramp Rate Improvement through Compressed Air Injection," Journal of Power and Energy, 2020.

[13] P. Perri, "A Flexible Generation and Energy Storage Solution," 11 November 2017. [Online]. Available: https://www.power-eng.com/articles/print/volume-121/issue-11/features/a-flexiblegeneration-and-energy-storage-solution.html. [Accessed August 2019].

[14] P. Dechamps, "Combined Cycle Gas Turbines".

[15] Mitsubishi Hitachi Power Systems, "M501F Series," Mitsubishi Hitachi Power Systems Global, [Online]. Available: https://www.mhps.com/products/gasturbines/lineup/m501f/index.html. [Accessed 7 February 2019]. 
[16] ofgem, "Electricity prices: Day-ahead baseload contracts - monthly average (GB)," Ofgem, August 2020. [Online]. Available: https://www.ofgem.gov.uk/data-portal/electricity-prices-day-aheadbaseload-contracts-monthly-average-gb. [Accessed 17 August 2020].

[17] T. Nikolaidis, "The Turbomatch Scheme," Thermal Power MSc Course Notes, Cranfield University, Bedford , 2015. 
$2021-02-20$

\title{
Impact of gas turbine flexibility improvements on combined cycle gas turbine performance
}

\author{
Abudu, Kamal
}

Elsevier

Abudu K, Igie U, Roumeliotis I, Hamilton R. (2021) Impact of gas turbine flexibility improvements on combined cycle gas turbine performance. Applied Thermal Engineering, Volume 189, May 2021, Article number 116703

https://doi.org/10.1016/j.applthermaleng.2021.116703

Downloaded from Cranfield Library Services E-Repository 